\title{
Revisão:
}

\section{Polifenóis em cacau e derivados: teores, fatores de variação e efeitos na saúde} Review:

\section{Polyphenols in cocoa and derivatives: factors of variation and health effects}

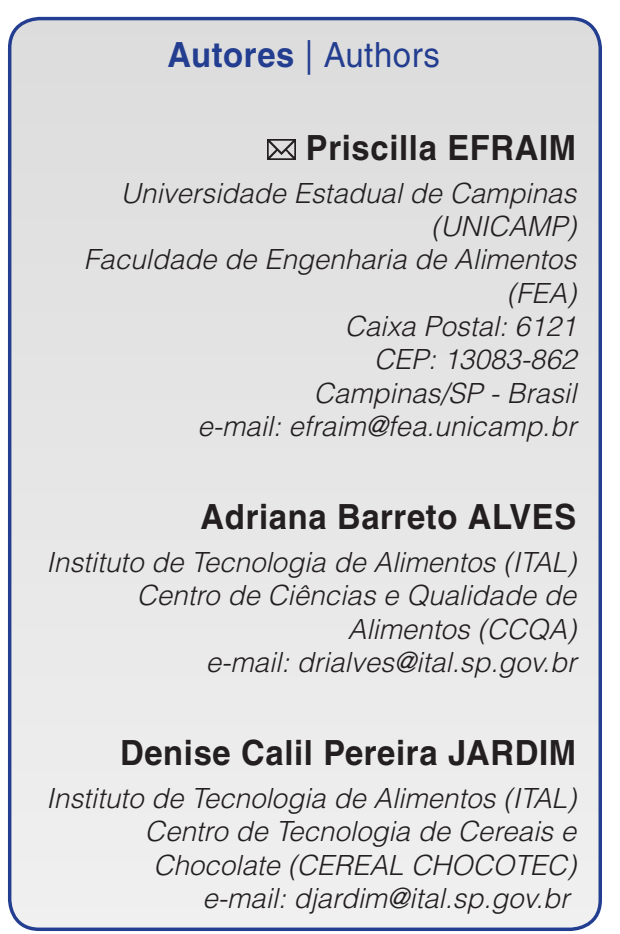

$\triangle$ Autor Correspondente / Corresponding Author

Recebido / Received: 22/02/2010 Aprovado / Approved: 28/03/2011

\section{Resumo}

O número de estudos sobre os polifenóis presentes no cacau tem aumentado consideravelmente nos últimos anos, principalmente relacionando-os aos benefícios à saúde humana. Mais recentemente, alguns trabalhos têm procurado prever o teor de polifenóis em produtos derivados de cacau com base no teor de sólidos desengordurados de cacau (SDC) e como o processamento afeta os polifenóis do cacau. As compilações da literatura, em geral, aprofundam os mecanismos dos efeitos benéficos dos compostos fenólicos do cacau no organismo humano. Esta revisão fornece um panorama das principais pesquisas relacionadas aos altos teores de polifenóis presentes no cacau e produtos derivados, bem como aos seus benefícios à saúde. Além disso, busca apresentar aspectos tecnológicos que influenciam o perfil dos compostos fenólicos durante as etapas de processamento. Pelas pesquisas científicas, a destruição dos compostos fenólicos naturalmente presentes nas sementes se dá principalmente nas etapas realizadas para o desenvolvimento do sabor de chocolate, as quais favorecem a diminuição da adstringência e do amargor. Os polifenóis, responsáveis pela capacidade antioxidante do cacau, são drasticamente reduzidos durante a fermentação das sementes e a alcalinização dos nibs e liquors, etapas que envolvem a ocorrência de complexas reações bioquímicas ou uma significativa variação do $\mathrm{pH}$. A produção de chocolate ao leite ou amargo, excluindo o chocolate branco, apresenta um enorme potencial para inovação tecnológica, visto a necessidade da manutenção destes compostos importantes para a saúde, sem prejuízo do sabor agradável, atributo esperado e de grande importância em produtos como o chocolate.

Palavras-chave: Cacau; Chocolate; Compostos fenólicos; Polifenóis; Fermentação; Alcalinização. 


\section{Summary}

The number of studies on cocoa polyphenols has increased significantly in recent years, mainly due to their benefits on human health. Recently, some researchers have studied how to predict the polyphenolic content of cocoa products based on the nonfat cocoa solids (NFCS), and how these contents are affected by the manufacturing steps. Most of the reviews found in the literature are focused on the mechanisms of the benefits of phenolics from cocoa on the human organism. The present review gives an overview of the main research carried out on the high polyphenolic contents of cocoa and its derivatives and on the health benefits. In addition it presents the technological aspects affecting the phenolic compounds profile during processing. Scientific research has indicated that destruction of the phenolic compounds naturally present in cocoa seeds occurs mainly during the stages carried out to develop the chocolate flavour, favouring a decrease in adstringency and bitterness. The polyphenols responsible for the antioxidant activity of cocoa, are drastically reduced during fermentation of the seeds and alkalization of the nibs and liquors, steps that involve the occurrence of complex biochemical reactions or a significant variation in $\mathrm{pH}$. The production of milk and dark chocolate, excluding white chocolate, has a great potential for technological innovation, due to the need to maintain these compounds important to the health, without prejudicing the pleasant flavour, which is a very important attribute in chocolate products.

Key words: Cocoa; Chocolate; Phenolic compounds; Polyphenols; Fermentation; Alkalization. 


\section{Introdução}

Os polifenóis, ou compostos fenólicos, têm sido largamente estudados em razão dos efeitos benéficos que propiciam à saúde, como uma potente atividade antioxidante na prevenção de reações oxidativas e de formação de radicais livres, bem como na proteção contra danos ao DNA das células (WOLLGAST e ANKLAN, 2000b). Outros efeitos positivos para a saúde são as propriedades anti-inflamatória, anticarcinogênica, antiaterogênica, antitrombótica, antimicrobiana, analgésica e vasodilatadora, comprovadas em estudos científicos (WOLLGAST e ANKLAN, 2000a; GOTTI et al., 2006).

Uva, vinho tinto, chá preto, chá verde, outras frutas, como maçã, morango, cereja, ameixa, pêssego e similares, além das sementes de cacau e o próprio chocolate, são ricos em flavanóis (YILMAZ, 2006).

Durante o processamento do cacau, ocorrem várias reações bioquímicas que podem alterar os teores de flavanóis e procianidinas nos produtos derivados. Esta revisão tem por objetivo apresentar os principais polifenóis presentes em cacau e produtos derivados, os benefícios à saúde que propiciam e como o processamento pode influenciar os teores desses compostos nos produtos obtidos.

\section{Principais polifenóis em cacau e chocolate}

Os compostos fenólicos são produtos do metabolismo secundário de plantas, sintetizados a partir de duas principais vias primárias: via do chiquimato e via do acetato (BRAVO, 1998).

Por se tratar de um amplo grupo, contendo mais de oito mil compostos já identificados, os compostos fenólicos podem ser distribuídos, dependendo da sua estrutura básica, em classes como fenóis simples, ácidos fenólicos, acetofenonas, ácidos fenilacéticos, ácidos hidroxicinâmicos, fenilpropenos, cumarinas, xantonas, antraquinonas, flavonoides, lignanas e ligninas, entre outras (BRAVO, 1998; WOLLGAST e ANKLAM, 2000a). De maneira simplificada, podem ser agrupados de acordo com a massa molecular, sendo que a classe de baixa massa molecular compreende os ácidos hidroxibenzoicos e hidroxicinâmicos; a classe de massa molecular intermediária, os flavonoides, considerada a maior e mais importante; e, entre os de alta massa molecular, estão os taninos condensados (procianidinas) e os taninos hidrolisáveis (ESCARPA e GONZALEZ, 2001).

Os flavonoides são derivados da reação de condensação do ácido cinâmico com grupos malonil-CoA (BLOOR, 2001) e a sua classificação depende do nível de oxidação verificado em suas estruturas químicas. De acordo com Seigler (1995), existem 14 tipos de flavonoides, sendo que a maioria dos compostos identificados pertence a apenas seis tipos: flavonas, flavanonas, flavonóis, flavanóis (também chamada de flavan-3-óis), isoflavonas e antocianinas (PETERSON e DWYER, 1998; ALVES, 2009).

\subsection{Polifenóis do cacau}

Os principais compostos fenólicos encontrados nas sementes de cacau são listados na Figura 1, estando dentro das classes dos taninos e dos flavonoides. Os flavonoides presentes incluem flavanóis, flavonóis, antocianinas, flavonas e flavanonas. Entre estes, os flavanóis são os mais abundantes, sendo a (+)-catequina e a (-)-epicatequina os principais representantes. A (-)-epicatequina tem sido reportada como o principal flavanol monomérico do cacau, representando aproximadamente 35\% do conteúdo total dos fenólicos (WOLLGAST e ANKLAM, 2000a). As sementes do cacau também contêm uma série complexa de procianidinas, formadas a partir da condensação de unidades individuais de catequinas ou epicatequinas, chamadas monômeros; por isso, são também conhecidas como taninos condensados. As procianidinas diferem na posição e na configuração das ligações entre os monômeros, e são encontradas em altas concentrações em cacau e chocolate, uvas e vinho, maçã e amendoim. Também são encontradas em quantidades menores em outros vegetais, principalmente frutas (De PASCUAL-TERESA et al., 2000). Por serem moléculas altamente hidroxiladas, podem formar compostos insolúveis ao se complexarem com carboidratos e proteínas. Durante a degustação de alimentos com alto teor destes compostos, pode ocorrer a complexação das procianidinas com proteínas da saliva, o que confere a sensação de adstringência (WOLLGAST e ANKLAN, 2000a).

\subsection{Biodisponibilidade dos polifenóis de cacau e derivados}

Dados relativos à permanência dos polifenóis no organismo humano são de grande importância, uma vez que alguns dos efeitos fisiológicos dos polifenóis encontrados nos alimentos dependem dos níveis presentes na circulação sanguínea. Porém, informações quanto a absorção, distribuição, metabolismo e eliminação dos polifenóis em seres humanos são escassos. A absorção e o metabolismo dos compostos fenólicos são determinados inicialmente pela sua estrutura química, a qual depende de fatores como o grau de glicosilação ou acilação, de sua estrutura básica (anel benzênico ou derivados de flavona), da possível conjugação com outros compostos fenólicos, da massa molecular, do grau de polimerização e da solubilidade (BRAVO, 1998).

Richelle et al. (1999) observaram que após o consumo de $80 \mathrm{~g}$ de chocolate amargo, a concentração 


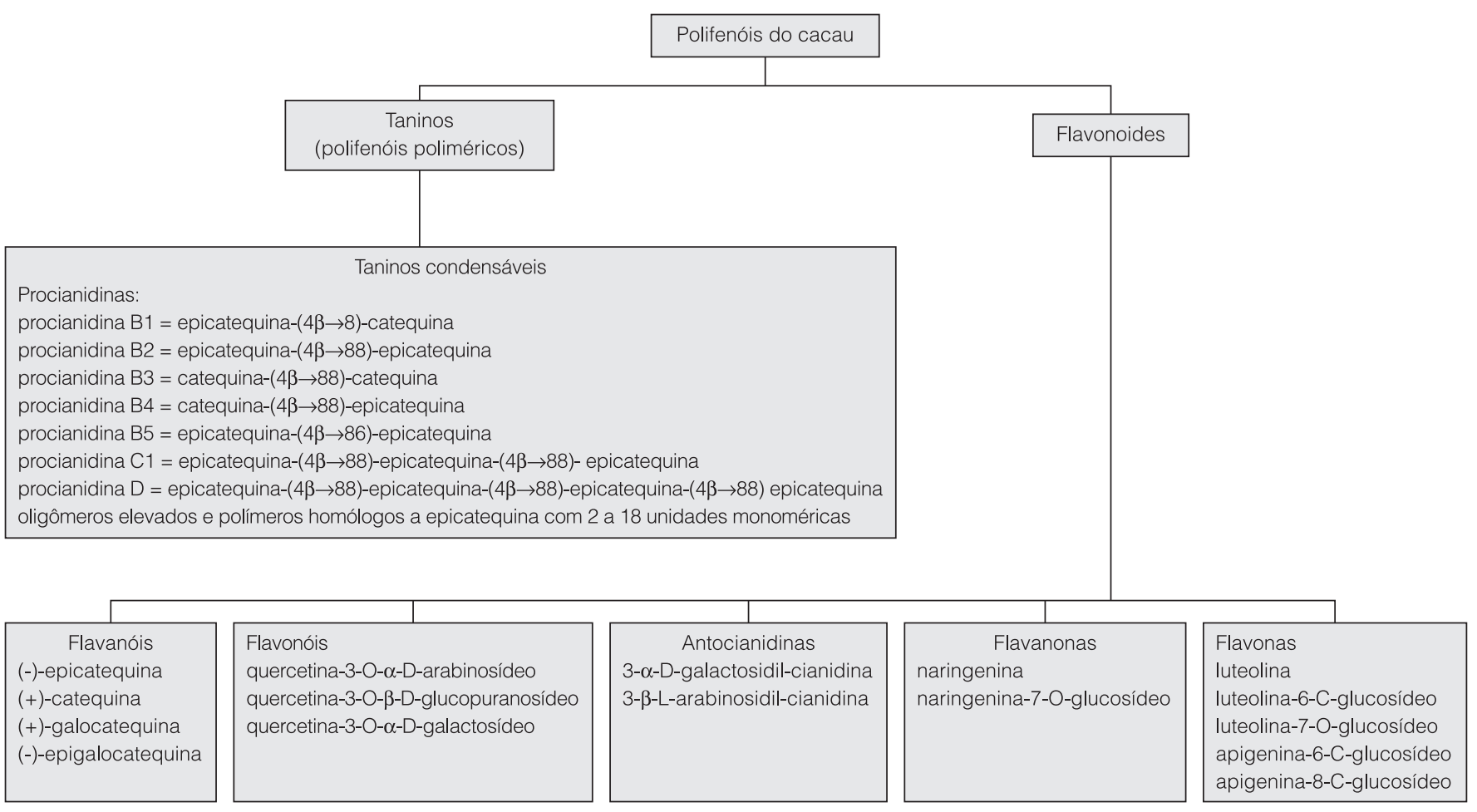

Figura 1. Principais polifenóis encontrados nas sementes de cacau. Fonte: Porter et al. (1991); Sanbongi et al. (1998); SanchezRabaneda et al. (2003); Counet et al. (2006).

de epicatequina em plasma de humanos aumentou, alcançando valor máximo entre 2 e $3 \mathrm{~h}$. Os níveis de epicatequina no plasma foram de $0,7 \mu \mathrm{mol} . \mathrm{L}^{-1}$ a partir da ingestão de $80 \mathrm{~g}$ de chocolate contendo $164 \mathrm{mg}$ de epicatequina, sendo que, antes da ingestão, o teor foi considerado muito baixo pelos autores, inferior ao limite de detecção do método utilizado. O estudo concluiu ainda que a epicatequina foi absorvida e eliminada rapidamente do plasma.

Holt et al. (2002) observaram teores consideravelmente mais baixos de dímeros de procianidinas $\left(16 \mathrm{nmol} . \mathrm{L}^{-1}\right)$ em relação aos de (-)-epicatequina $\left(2,61 \mu \mathrm{mol} . \mathrm{L}^{-1}\right)$ e $(+)$-catequina $\left(0,13 \mu \mathrm{mol} . \mathrm{L}^{-1}\right)$ no plasma humano após $30 \mathrm{~min}$ do consumo de uma bebida à base de cacau com alto teor desses compostos. Entre os flavanóis presentes na bebida, a epicatequina foi encontrada em quantidade dez vezes maior que a catequina no plasma, sendo que, na bebida, sua quantidade era apenas três vezes maior que a de catequina. Os resultados obtidos sugerem que, in vivo, ocorra preferencialmente a absorção de epicatequina ou a modificação isomérica da catequina, transformando-a em epicatequina.

Considerando que polifenóis podem formam complexos com proteínas, a adição de leite, por exemplo, em chá preto ou chocolate, pode causar a redução da biodisponibilidade dos polifenóis do chá ou do cacau. Serafini et al. (1996) verificaram que a ingestão de chá verde ou preto aumenta significativamente a capacidade antioxidante no plasma total, mas a adição de leite neutraliza este efeito. Outros autores, entretanto, observaram que a adição de leite em chá verde ou preto em quantidades menores do que as utilizadas por Serafini et al. (1996) não afetaram a concentração de catequina e quercetina na corrente sanguínea, em comparação com chá puro (infusão em água) (HOLLMAN et al., 2001; van HET HOF et al., 1998).

Depréz et al. (2001) demonstraram que catequinas e epicatequinas (monômeros), e procianidinas com até três monômeros condensados foram absorvidas pelo trato gastrointestinal de forma intacta e que dímeros e trímeros mostraram-se permeáveis a um modelo de predição de absorção celular passiva no intestino (células de adenocarcinoma de cólon humano - Caco-2). Os autores verificaram que procianidinas com mais de três monômeros condensados não podem ser absorvidas diretamente pelo lúmen gastrointestinal, sendo necessária sua quebra em monômeros ou polímeros menores em meio ácido no estômago para serem absorvidas.

Schramm et al. (2003) estudaram o efeito da composição nutricional de dietas na absorção e na farmacocinética de flavanóis de cacau no organismo e concluíram que há influência do tipo de alimento consumido, sendo que maior absorção foi observada com dieta rica em carboidratos. Contudo, os autores alertam 
para a necessidade de pesquisas adicionais sobre o tipo de carboidrato que pode causar os efeitos observados.

\section{Benefícios dos polifenóis à saúde}

O cacau tem um longo histórico de utilização como alimento e como medicamento (KWIK-URIBE, 2005). Os europeus, no século XVI, utilizavam o cacau e o chocolate (líquido) como veículos de medicamentos, além de serem considerados por si só como medicamentos. Na forma isolada ou em combinação com ervas, plantas e outros suplementos alimentares, o cacau e o chocolate eram utilizados no tratamento de doenças, como desordens digestivas, dores de cabeça, inflamações e insônias (KWIK-URIBE, 2005).

De acordo com Schroeter et al. (2006), a epicatequina é o componente ativo do cacau responsável pelos efeitos benéficos à saúde vascular a ele associados.

Há um crescente número de estudos que comprovam os benefícios à saúde propiciados pelos flavonoides na prevenção e na atenuação do risco de contração de determinadas doenças. Alguns dos efeitos benéficos são discutidos a seguir.

\subsection{Capacidade antioxidante}

As espécies reativas de oxigênio (ERO) têm papel importante em muitos processos biológicos. São geradas durante reações de transferência de elétrons em células aeróbicas, especialmente pela cadeia transportadora de elétrons mitocondrial (HALLIWEL e GUTTERIDGE, 1990 apud COENTRÃO, 2005). Incluem o radical hidróxido $(\bullet \mathrm{OH})$, ânion superóxido $\left(\mathrm{O}_{2} \bullet\right)^{-}$, peróxido de hidrogênio $\left(\mathrm{H}_{2} \mathrm{O}_{2}\right)$, ácido hipoclórico $(\mathrm{HOCl})$ e oxigênio singlete $\left({ }^{1} \mathrm{O}_{2}\right)$ (SIES, 1991). Quando produzidos em excesso e não destruídos pelo sistema antioxidante de defesa do organismo, podem reagir facilmente com o DNA, as proteínas e os lipídios, provocando doenças como câncer, aterosclerose, injúria da mucosa gástrica e envelhecimento (HALLIWELL, 1990). Para auxiliar os sistemas antioxidantes de defesa, é desejável a ingestão de substâncias com capacidade antioxidante para combater o excesso de ERO. Alguns polifenóis, como o flavonol quercetina e os flavanóis catequina e epicatequina, além de carotenoides e vitaminas $\mathrm{C}$ e $\mathrm{E}$, apresentam elevada atividade antioxidante (JACOB e BURRI, 1996).

A atividade antioxidante do cacau foi mensurada em diversos estudos. Sanbongi et al. (1998), avaliaram o efeito in vitro de um extrato rico em flavonoides obtido a partir de liquor de cacau em solução alcoólica $80 \%$. Os resultados indicaram que não apenas catequinas e epicatequinas apresentaram efeito antioxidante, como também quercetina, quercetina-3-glicosídeo, quercetina3-arabinosídeo e dideoxiclovamida. Mao et al. (2000) demonstraram a elevada atividade antioxidante in vitro das procianidinas do cacau, tanto na fase de indução (atuando como antioxidante preventivo), como na fase de propagação (atuando como antioxidante de quebra de cadeias) da peroxidação de lipídios. Os mesmos compostos mostraram-se capazes, ainda, de retardar o ataque de lipídios durante a fase de quebra das reações de pró-oxidação, inibindo totalmente a formação de produtos de degradação. Esses efeitos foram observados mesmo em concentrações submicromoleculares, indicando que as procianidinas do cacau podem atuar como inibidoras de inflamações agudas. Dados apresentados por Steinberg et al. (2003) coletados a partir de outros estudos demonstraram que a capacidade antioxidante das procianidinas de cacau e derivados foi maior em comparação com outros alimentos (Tabela 1).

Em estudos realizados in vivo em humanos, as catequinas foram responsáveis pelo aumento da atividade antioxidante, diminuição de malonaldeído e peróxido lipídico no plasma, aumento das concentrações de ascorbato no plasma, diminuição da absorção de ferro não-heme e aumento da resistência do LDL-colesterol à oxidação (WILLIAMSON e MANACH, 2005).

\subsection{Atividade cardioprotetora}

As plaquetas são componentes sanguíneos cuja principal função é a formação de coágulos em locais do corpo que tenham sofrido danos, reduzindo a perda sanguínea e auxiliando a cicatrização de ferimentos. Por outro lado, a elevada atividade das plaquetas pode ser indesejável, especialmente em casos de doenças cardiovasculares. Fatores como altos níveis de colesterol, diabetes, fumo e obesidade levam ao aumento da reatividade das plaquetas, levando à sua agregação e à formação de coágulos que podem desencadear um ataque cardíaco (KWIK-URIBE, 2005).

O consumo de produtos de cacau com alto teor de flavanóis e procianidinas diminui a tendência de agregação

Tabela 1. Capacidade antioxidante de alguns alimentos e bebidas.

\begin{tabular}{lc}
$\begin{array}{c}\text { Alimento } \\
\text { ou bebida }\end{array}$ & $\begin{array}{c}\text { ORAC * } \\
\text { (mmol de equivalentes } \\
\text { Trolox.100 } \text { g }^{-1} \text { ) }\end{array}$ \\
\hline Liquor de cacau & 40,0 \\
Chocolate amargo & 13,0 \\
Chocolate ao leite & 6,7 \\
Maçã & 0,2 \\
Vinho Tinto & 0,7 \\
Infusão chá preto & 1,6 \\
(2 g chá.200 $\mathrm{mL}^{-1}$ água) & \\
\hline
\end{tabular}

*(ORAC) Capacidade de absorção de radicais de oxigênio. Fonte: Arts et al. (2000); Hammerstone et al. (2000); Osakabe et al. (1998); Wang et al. (2000); Cao et al. (1996, 1998 apud STEINBERG et al., 2003). 
das plaquetas e, portanto, a formação de coágulos (KWIK-URIBE, 2005). Além disso, o risco de contração de doenças cardiovasculares diminui quando são administradas doses terapêuticas de ácido acetilsalicílico e suplementos antioxidantes, pois o tratamento com estes compostos favorece uma significativa diminuição na incidência de eventos coronários, minimizando o risco de infarto do miocárdio e de derrame cerebral (LEKSTRON e BELL, 1991; HANNEKENS, 1994).

O consumo de bebidas à base de cacau com elevado teor de flavanóis e procianidinas pode favorecer a saúde cardiovascular por meio do aumento dos níveis de óxido nítrico (NO) por reflexo da melhoria das funções endoteliais (SCHNORR et al., 2008). O NO, quando em níveis normais no organismo, apresenta efeito de relaxamento dos vasos endoteliais. Deve-se considerar que baixas concentrações do aminoácido L-arginina nos tecidos e vasos sanguíneos estão relacionadas com doenças inflamatórias por causa da diminuição da biodisponibilidade de NO, uma vez que os níveis da enzima arginase aumentam, levando à diminuição dos níveis de NO. Schnorr et al. (2008) avaliaram o efeito do consumo de bebida à base de cacau com alto teor de flavanóis por dez voluntários saudáveis e verificaram diminuição da atividade da enzima arginase e melhoria da função vascular.

Considerando que pessoas diabéticas apresentam baixa biodisponibilidade de NO, Balzer et al. (2008) avaliaram a proteção vascular pelo impacto de dietas à base de bebidas de cacau contendo teores variáveis de flavanóis e procianidinas administradas diariamente a pacientes diabéticos. Os resultados estão apresentados no Quadro 1, demonstrando aumento da biodisponibilidade de NO. Cooper et al. (2008) avaliaram como os polifenóis do cacau podem afetar o sistema vascular, com dependência das concentrações de NO como alvo central.

\subsection{Atividade anti-inflamatória}

Embora algumas reações inflamatórias no organismo sejam necessárias para repelir bactérias estranhas e vírus, em casos em que se apresentam problemas cardiovasculares, respostas inflamatórias podem resultar em ataques cardíacos. Estudos in vitro realizados com flavanóis e procianidinas do cacau demonstraram que estes possuem capacidade de reduzir a produção de compostos pró-inflamatórios e de aumentar a produção de pelo menos uma molécula com propriedades anti-inflamatórias. Rein et al. (2000) demonstraram a capacidade dos flavanóis modularem etapas-chave que regulam a formação de moléculas pró-inflamatórias e de afetarem enzimas envolvidas diretamente na formação de tais moléculas. Contudo, o grau de condensação (monômeros, dímeros, trímeros, etc.) dos flavanóis interferiu em sua atividade.

Osakabe et al. (1998) também verificaram, em estudo realizado in vivo, que a ingestão de flavanóis e procianidinas favoreceu a produção de compostos anti-inflamatórios. Foi demonstrada ainda propriedade anti-inflamatória por meio da redução da severidade de lesões gástricas induzidas pelo consumo de álcool. Neste sentido, concluiu-se que tais compostos oferecem proteção cardiovascular por causa da capacidade de modularem moléculas envolvidas em processos inflamatórios.

\subsection{Compilação de estudos sobre os efeitos dos polifenóis na saúde}

No Quadro 1, são apresentados dados compilados de diversas referências quanto à dose ingerida, ao tipo de produto oferecido e aos efeitos observados. A maioria dos estudos que avaliaram o efeito de doses agudas (dose única) utilizou teores próximos a 900 mg de flavanóis e procianidinas por porção servida e a maioria dos estudos que avaliaram doses crônicas (consumo por período mais prolongado), utilizou teores próximos a $300 \mathrm{mg}$ de flavanóis e procianidinas.porção ${ }^{-1} \cdot \mathrm{dia}^{-1}$.

\subsection{Dados sobre ingestão e consumo}

O chocolate contribui com o consumo per capita de antioxidantes na União Europeia e nos Estados Unidos, sendo, neste último, a terceira mais importante fonte de antioxidantes da dieta da população (VINSON et al., 2006). Gu et al. (2004) calcularam, por meio de dados do USDA (United States Department of Agriculture), que o consumo per capita de procianidinas da população americana é de $58 \mathrm{mg} \cdot \mathrm{dia}^{-1}$, sendo o chocolate uma das principais fontes. Arts et al. (2001) estimaram que o consumo médio de flavanóis na Holanda é de 50 mg. dia ${ }^{-1}$, sendo que as principais fontes são o chá, a maçã e o chocolate.

Para declaração em rótulo de benefícios à saúde, fabricantes de chocolates com altos teores de polifenóis se apóiam em estudos científicos para a definição das seguintes quantidades de polifenóis em seus produtos: Linha Cocoavia ${ }^{\circledR}$ (Mars Inc.) -200 mg de flavanóis e procianidinas por porção; Linha Acticoa (Barry Callebaut) -240 mg de flavanóis e procianidinas em $40 \mathrm{~g}$ de chocolate amargo (50 e $70 \%$ de cacau) e 60 mg de flavanóis e procianidinas em $40 \mathrm{~g}$ de chocolate ao leite; produto "Antioxidant milk chocolate" (Hershey's) -260 mg flavanóis e procianidinas em $40 \mathrm{~g}$ e produto "Hersheys whole beans" -180 mg de flavanóis e procianidinas em $40 \mathrm{~g}$ (COCOAVIA, 2011; ACTICOA, 2011; HERSHEY'S, 2010). 


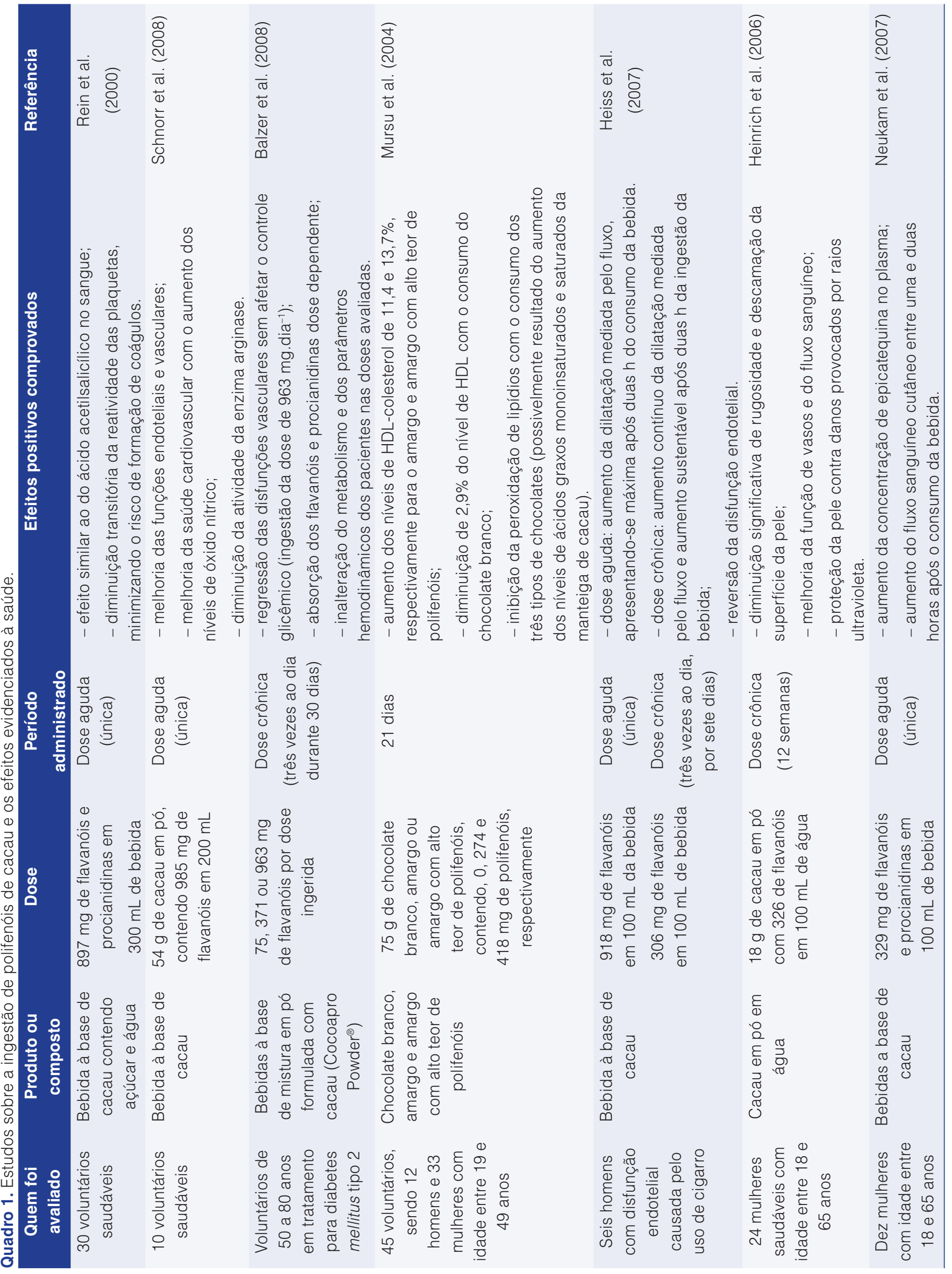


Revisão: polifenóis em cacau e derivados: teores, fatores de variação e efeitos na saúde EFRAIM, P. et al.

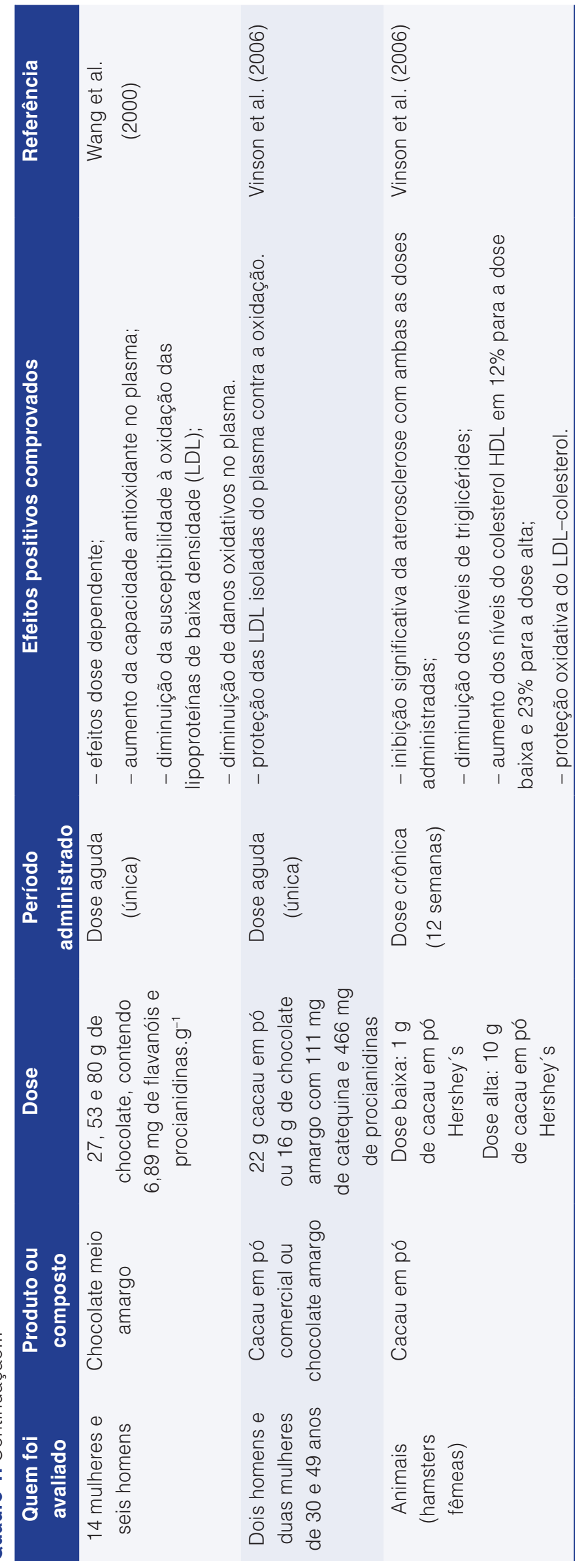


Cabe destacar que $58 \%$ dos consumidores de chocolate da Europa preferem o tipo ao leite, seguidos de $43 \%$ que preferem o tipo amargo. Na Inglaterra, a diferença na proporção de pessoas que preferem chocolate ao leite ao amargo é maior (61 versus 35\%). $\mathrm{Na}$ Espanha, as bebidas à base de cacau e chocolate são mais populares que o chocolate em si. Nos Estados Unidos, como no Brasil, há também maior preferência por chocolate ao leite, mas $87 \%$ do chocolate consumido é combinado com nozes, castanhas, frutas secas e outros (COOPER et al., 2008).

\section{Teores de polifenóis em cacau e derivados}

As sementes de cacau possuem de 6 a $8 \%$ de compostos fenólicos, em peso seco, sendo $60 \%$ (+)-catequina, (-)-epicatequina e procianidinas (ZUMBÉ, 1998; BRITO, 2000). Em sementes de cacau não fermentadas in natura, a quantidade de (-)-epicatequina é vinte vezes maior que a de (+)-catequina (KWIK-URIBE, 2005), enquanto que, no chocolate, observa-se teor ao redor de seis vezes maior (KEEN, 2001). De acordo com Lee et al. (2003), o cacau possui teor mais alto de flavonoides por porção de consumo que chás e vinho tinto.

A quantidade de compostos fenólicos presentes no cacau e, consequentemente, em chocolates, depende não apenas de características genéticas, mas também de outros fatores, como clima (temperatura e umidade), propriedades químicas do solo, região de cultivo, entre outros aspectos discutidos nesta revisão (JALIL e ISMAIL, 2008). Em geral, as características de amargor e adstringência do cacau e de produtos derivados são atribuídas aos compostos fenólicos, embora a literatura reporte outros fatores, como a presença de certos aminoácidos e a complexação de peptídeos com metilxantinas, que também contribuem para o amargor e a adstringência (van DER GREEF et al., 1987 apud BRITO, 2000; PICKENHAGEN et al., 1975).

Entre as antocianinas identificadas em sementes de cacau, encontram-se a cianidina-3-arabinosídeo e a cianidina-3-galactosídeo, as quais representam cerca de $4 \%$ do conteúdo total de polifenóis das sementes. Entretanto, tais compostos podem sofrer hidrólise durante o processo de fermentação do cacau (WOLLGAST e ANKLAM, 2000a).

$\mathrm{Na}$ Tabela 2, são apresentados os teores de polifenóis totais, flavanóis e procianidinas $\left(\mathrm{mg} \mathrm{g}^{-1}\right) \mathrm{em}$ produtos derivados de cacau, compilados de diversos trabalhos, nos quais se observam grandes variações discutidas a seguir.

Kealey et al. $(1998,2000)$ encontraram teores consideravelmente distintos de polifenóis em sementes não fermentadas, apesar de terem sido utilizados métodos de extração e detecção similares. No primeiro estudo, foram usadas sementes da variedade SIAL 659 de procedência não informada e, no segundo, de Sulawesi, variedade não informada. Nesse caso, as variações possivelmente ocorreram por diferenças genéticas e/ ou edafoclimáticas. Os valores encontrados por Kim e Keeney (1984) para amêndoas fermentadas e secas de diferentes procedências variaram de forma considerável. Além das mesmas causas levantadas para as sementes não fermentadas, a forma de beneficiamento também pode influenciar. Adamson et al. (1999) e Natsume et al. (2000) encontraram teores de polifenóis similares em liquors de cacau de mesma procedência (Costa do Marfim). Em relação à grande diferença observada nos teores em liquors de Sanchez e Costa do Marfim, Adamson et al. (1999) esclarecem que, em Sanchez, as amêndoas de cacau são pouco ou não fermentadas e, na Costa do Marfim, a fermentação ocorre por períodos maiores, o que possivelmente explicaria o teor mais alto de polifenóis da amostra de Sanchez em comparação com a da Costa do Marfim. Os mesmos autores ressaltam ainda que os teores de procianidinas encontrados nos chocolates amargos podem ter sido mais baixos que o esperado por ter sido utilizado, em sua produção, liquor alcalinizado. A influência da fermentação e da alcalinização nos teores de polifenóis será discutida neste artigo.

Andrés-Lacueva et al. (2008), que avaliaram 11 diferentes marcas espanholas de cacau em pó, encontraram teores totais de flavonóis (quercetina, quercetina-3-glucoronídeo, isoquercetina e quercetina3-arabinosídeo) na faixa de 9,08 a 81,31 $\mu \mathrm{g} \cdot \mathrm{g}^{-1}$. Ao comparar os valores encontrados em base seca com outros alimentos, os autores destacam que o cacau em pó fornece quantidade de quercetina próxima à encontrada em brócolis congelado (0,91-3,52 mg.100 $\left.\mathrm{g}^{-1}\right)$; em maçã Golden com casca (1,56-4,40 mg.100 g $\left.\mathrm{g}^{-1}\right)$ e em uva, variedade Vitis vinifera $\left(0,00-3,98 \mathrm{mg} .100 \mathrm{~g}^{-1}\right)$. Entretanto, uma vez que o cacau em pó não é o produto final a ser consumido, a quantidade de flavonóis fornecida por porção de alimentos ou bebidas formuladas com cacau em pó (0,083-1,3 mg.20 $\left.\mathrm{g}^{-1}\right)$ pode ser menor em relação a outras fontes de alimentos que, em geral, são consumidos em porções maiores (em média, 200 g), como maçã, brócolis e uva.

Wollgast e Anklam (2000a) também atribuem as variações nos teores de polifenóis encontrados em cacau e derivados às diferenças nas metodologias analíticas empregadas para extração e quantificação dos compostos, além da influência genética, edafoclimática e dos processos tecnológicos utilizados para a obtenção dos produtos avaliados, entre outros motivos. 


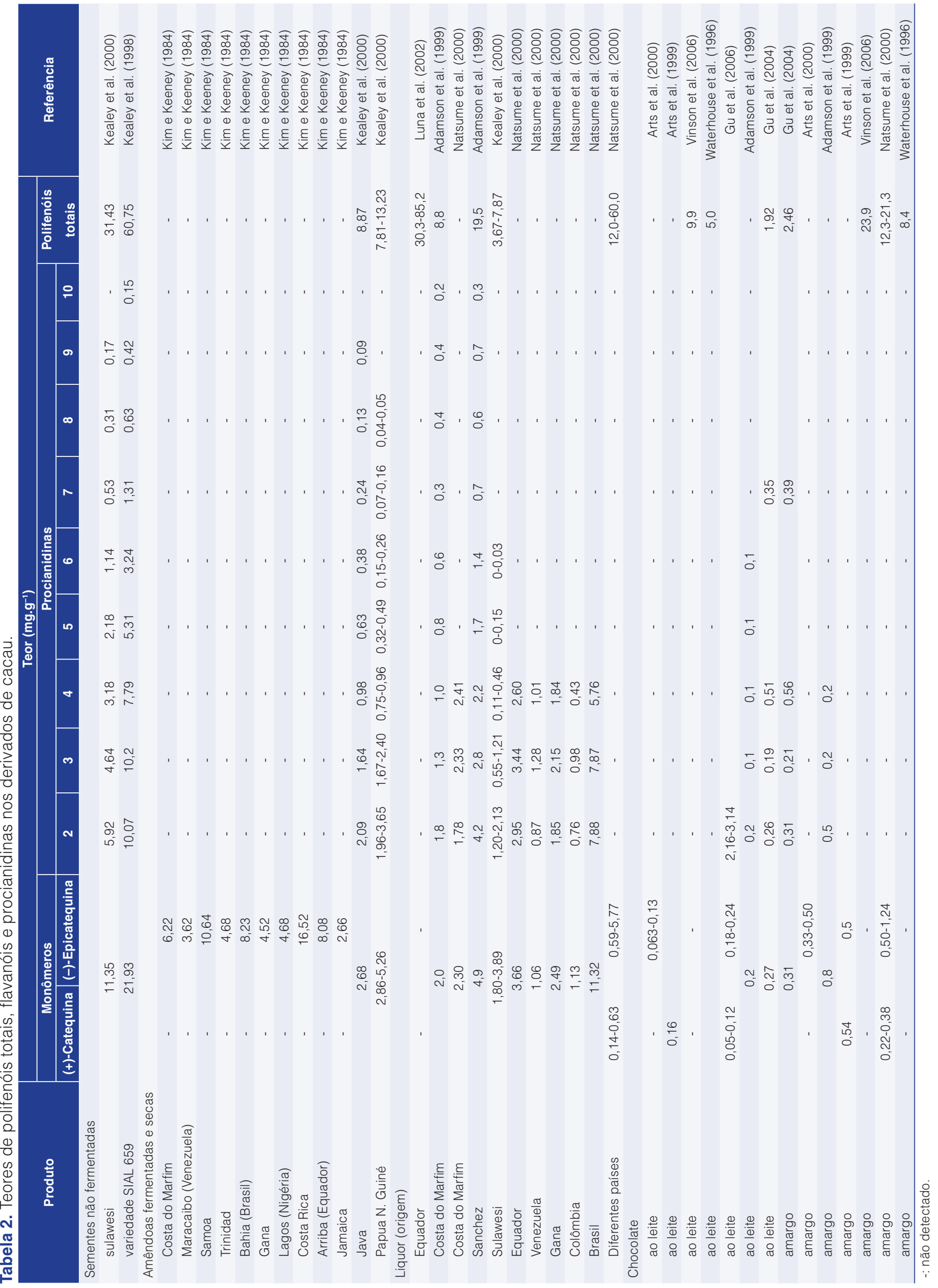


Revisão: polifenóis em cacau e derivados: teores, fatores de variação e efeitos na saúde EFRAIM, P. et al.

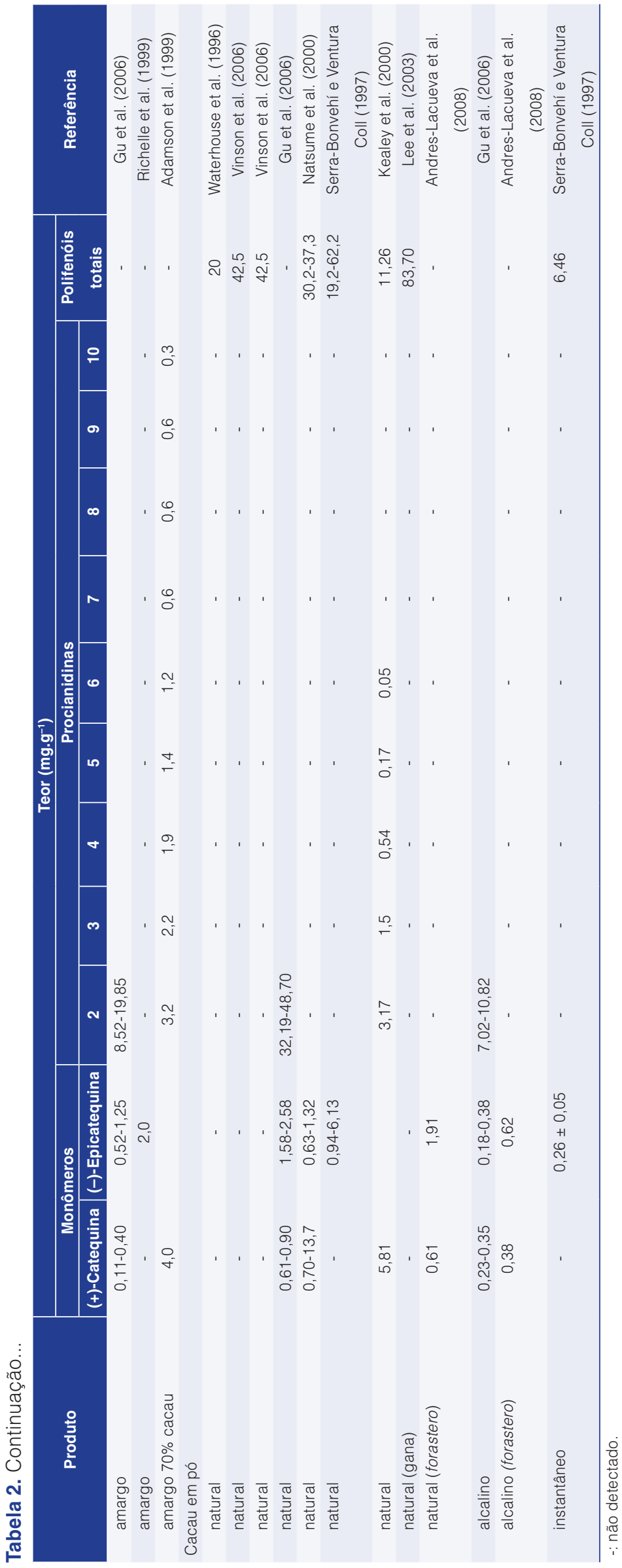




\subsection{Marcadores de polifenóis}

A utilização do teor de sólidos desengordurados de cacau (SDC) como marcador ou forma de prever o teor de polifenóis tem sido outra recente fonte de estudos. Miller et al. (2006) encontraram forte correlação entre os teores de SDC e de polifenóis e procianidinas e a capacidade de absorção do radical oxigênio (ORAC), em grande variedade de produtos contendo cacau nos EUA. Gu et al. (2006) encontraram forte correlação entre o teor de SDC e de procianidinas (até decâmeros) em cacau em pó e chocolate amargo, eliminando-se variações individuais e considerando as médias obtidas dentro das categoriais de produtos avaliadas. Cooper et al. (2007) demonstraram haver considerável variação no teor individual de polifenóis em 68 amostras de chocolate avaliadas. Contudo, foram observadas relações preditivas entre os teores de (-)-epicatequina e de outros polifenóis individuais presentes no chocolate, especialmente as procianidinas $\mathrm{B} 2$ e $\mathrm{C} 1$. Estudos realizados com ampla variedade de amostras de chocolate podem revelar o quanto a relação entre o teor de SDC e a concentração de polifenóis (totais e individuais) é significativa, e como tal relação pode ser utilizada na identificação de chocolates com alto teor de polifenóis, especialmente a epicatequina, considerada por Schroeter et al. (2006) mais benéfica à saúde. Neste sentido, Cooper et al. (2008) avaliaram 69 amostras comerciais de chocolate produzidas em vários países quanto ao potencial preditivo entre SDC e o teor de polifenóis por meio de análise de regressão linear. Do total de amostras avaliadas, 39 declaravam no rótulo o teor de ingredientes de cacau (liquor, manteiga e /ou pó de cacau), que era de 20 a 100\%. O modelo sugerido foi preditivo quanto ao teor de compostos fenólicos totais e ao teor de SDC em chocolate amargo puro. Polifenóis individuais, como a epicatequina, mostraram relação menos preditiva, especialmente em chocolate do tipo ao leite ou contendo ingredientes agregados.

Uma possível causa seriam as diferentes sensibilidades dos métodos empregados, isto é, o método por cromatografia líquida de alta eficiência, empregado na determinação de polifenóis individuais, é menos sensível a interferências de proteínas que o método de FolinCiocalteu usado na quantificação de polifenóis totais. Ou seja, o método de Folin-Ciocalteu mostra-se limitado em função da falta de especificidade, uma vez que outros produtos da oxidação ocorrida durante determinação podem interferir, superestimando os teores de polifenóis dos produtos analisados (AINSWORTH e GILLESPIE, 2007 apud RAMIREZ-SANCHEZ et al., 2010). Destacam-se ainda as condições de processo utilizadas na fabricação dos diferentes tipos de chocolate, as quais podem afetar os teores de monômeros e oligômeros, bem como a razão entre os mesmos (COOPER et al., 2008).

\section{Fatores que influenciam os teores de polifenóis em cacau e produtos derivados}

Os teores de polifenóis em cacau podem variar de acordo com a origem geográfica, a variedade da planta, o clima, o tipo de solo e a região de plantio (fatores agronômicos e ambientais). As diferentes etapas da transformação do cacau em chocolate também podem influenciar no teor de polifenóis dos produtos finais (fatores de processo) (RAMIREZ-SANCHEZ et al., 2010).

\subsection{Fatores intrínsecos}

Embora novas classificações genéticas estejam atualmente sendo estudadas, a mais utilizada divide os tipos de cacau em dois principais grupos genéticos, com base em características morfológicas e origens geográficas: Criollo, cujas sementes são normalmente grandes e os cotilédones apresentam coloração branca ou violeta clara. Estes, quando corretamente processados, originam chocolates e outros derivados com sabor mais suave e frutado. Outro grupo é Forastero Amazônico, caracterizado por sementes intensamente pigmentadas, que originam chocolates e outros derivados com sabor mais intenso, amargo e adstringente (MOTAMAYOR et al., 2008; BECKETT, 2009). O tipo Trinitário é resultante da hibridização dos grupos anteriores, sendo que os cotilédones das sementes podem apresentar coloração variando de branca à violeta-pálida (PIRES, 2003; MOTAMAYOR et al., 2008). Sementes de cacau do grupo Forastero contêm de 30 a 60\% mais compostos fenólicos que as do grupo Criollo (KEALEY et al., 1998; BRITO, 2000). Isso possivelmente se relaciona ao maior amargor e à adstringência verificados em produtos derivados de cacau Forastero, em comparação com produtos derivados de cacau Criollo.

Kealey et al. (2001), Efraim et al. (2006) e Niemenak et al. (2006), também demonstraram haver variação no teor de polifenóis em função de características genéticas e da variedade de cacau. Kim e Keeney (1984) avaliaram o teor de (-)-epicatequina de oito genótipos de cacaueiro provenientes de Itabuna (Bahia, Brasil) dos grupos Forastero Amazônico, Híbridos TrinidadJamaica, Trinitário e Forastero Nacional, encontraram teores mais altos de (-)-epicatequina no genótipo SIC-250 (Forastero Amazônico) e mais baixos nos genótipos ICS (híbridos Trinidad-Jamaica), em relação aos demais materiais estudados. Capriles de Reyes et al. (1964 apud NOJOSA et al., 2003) encontraram teores mais altos de polifenóis no genótipo IMC 67 em relação aos demais avaliados e, associaram este resultado à maior resistência a pragas e doenças desse genótipo. Por outro lado, Meifrein e Tanguy (1967); Daguenet e Parvais (1991); Omokolo et al. (1996) e Efraim et al. (2006) encontraram teores mais baixos de polifenóis no genótipo ICS 95, que apresenta maior susceptibilidade a pragas e 
doenças. Pelos diversos trabalhos avaliados, observa-se que genótipos do grupo Forastero ou descendentes apresentam teores de polifenóis mais altos que os genótipos dos grupos Criollo e Trinitário.

\subsection{Fatores relacionados ao processo}

Para a obtenção de produtos derivados de cacau, as sementes, após colheita e quebra dos frutos, são submetidas a várias etapas: fermentação, secagem, torração, moagem das amêndoas inteiras ou dos nibs (fragmentos das amêndoas de cacau isentos de casca e gérmen) para a obtenção da massa de cacau, moagem fina para obtenção do liquor de cacau, e prensagem do liquor para a obtenção da manteiga de cacau e da torta. A partir da torta de cacau, origina-se o cacau em pó, que poderá ainda ser alcalinizado. O liquor, a manteiga e o cacau em pó são os principais produtos utilizados na fabricação de chocolates e alimentos derivados de cacau. As etapas que correspondem ao processamento do chocolate a partir de liquor e manteiga de cacau são, basicamente, mistura, refino, conchagem, temperagem, resfriamento e moldagem/recobrimento.

A adstringência e o amargor são atribuídos aos polifenóis juntamente com os alcaloides teobromina e cafeína, além de aminoácidos, peptídeos, pirazinas e dicetopiperazinas, também presentes naturalmente nos produtos derivados (PICKENHAGEN et al., 1975; SERRABONVEHÍ e VENTURA COLL, 1997; LUNA et al., 2002; MISNAWI et al., 2005).

Durante as etapas de processamento do cacau para a produção de chocolate, Cross (1999) observou que os flavanóis sofrem uma série de reações químicas, como oxidação, complexação e lixiviação, que, associadas às demais reações em curso - como a hidrólise de proteínas a aminoácidos, e de açúcares - levam à formação de compostos aromáticos, contribuindo significativamente para a formação do sabor desejável e a redução do amargor e da adstringência.

\subsubsection{Influência da fermentação}

A fermentação das sementes é essencial para a obtenção de produtos de boa qualidade sensorial. Durante esta etapa, ocorrem reações bioquímicas complexas, importantes para o desenvolvimento dos compostos precursores do sabor característico do chocolate. O tempo requerido para a fermentação das sementes é variável, dependendo do tipo de cacau, das condições climáticas, das quantidades a serem fermentadas, entre outros aspectos. As sementes Forastero, grupo mundialmente predominante, devem ser fermentadas, em geral, por períodos superiores a cinco dias (BECKETT, 2009).
Durante a fermentação, com a morte do embrião, os polifenóis entram em contato com as enzimas polifenoloxidase e glicosidase (responsáveis pela hidrólise das antocianidinas) presentes nas sementes (FORSYTH e QUESNEL, 1958; HANSEN et al., 1998; BRITO, 2000; BECKETT, 2009), sofrendo oxidação, complexação com proteínas e formação de quinonas, as quais sofrem condensação covalente com grupos reativos de aminoácidos, peptídeos, proteínas e fibras (FORSYTH e QUESNEL, 1958). O teor de antocianinas decresce, chegando a $7 \%$ do valor inicial, e grande parte dessa perda ocorre entre o primeiro e o terceiro dia (CROSS et al., 1982; BRITO, 2000). Ainda durante a fermentação, o teor de polifenóis totais diminui cerca de $70 \%$, sendo que a (-)-epicatequina, principal substrato da enzima polifenoloxidase, sofre redução de $90 \%$ de sua concentração inicial.

Os teores de polifenóis também são influenciados pela estabilidade que apresentam em meios ácidos ou básicos (ZHU et al., 1998). Cooper et al. (2008) reportaram não haver evidências suficientes quanto aos reais mecanismos que levam à perda de flavanóis e procianidinas. No entanto, destacaram a possibilidade de tais compostos serem utilizados para a formação de taninos de maior massa molecular, uma vez que o perfil, e não o teor total dos polifenóis, sofre alteração após a fermentação durante o processamento das amêndoas para a obtenção de liquor e cacau em pó (COOPER et al., 2008).

A polimerização e a complexação dos polifenóis com proteínas durante a fermentação provocam a diminuição da solubilidade dos mesmos e a redução da adstringência. Ao mesmo tempo, catequinas formam taninos complexos e antocianinas são hidrolisadas a antocianidinas, que se polimerizam (SERRA-BONVEHÍ e VENTURA COLL, 1997).

A Tabela 3 apresenta dados dos teores de flavanóis de sementes de cacau desengorduradas mensurados durante a etapa de fermentação. Cabe destacar que as sementes de cacau contêm, normalmente, de 50 a 57\% de manteiga de cacau.

Kealey et al. (1998) observaram perdas de 53 a $74 \%$ de flavanóis e procianidinas durante a etapa de fermentação. Kealey et al. (2001) quantificaram os teores de polifenóis de sementes de cacau durante 0 processamento e, observaram perdas de 32, 47, 57 e $87 \%$ dos polifenóis em relação aos teores iniciais de sementes não fermentadas nas etapas de fermentação, torração, obtenção de liquor natural e obtenção de liquor alcalinizado, respectivamente. Efraim (2004) estudou a adição de bissulfito de sódio e sulfato de cobre durante a fermentação de sementes de cacau para inibir a ação de enzimas responsáveis pela degradação dos compostos fenólicos. A adição de 5 mg de bissulfito de 
Revisão: polifenóis em cacau e derivados: teores, fatores de variação e efeitos na saúde

EFRAIM, P. et al.

Tabela 3. Teores de flavanóis e procianidinas $\left(\mathrm{mg} . \mathrm{g}^{-1}\right)$ em base seca e desengordurada, em sementes de cacau, ao longo da fermentação.

\begin{tabular}{|c|c|c|c|c|c|}
\hline \multirow{2}{*}{$\begin{array}{l}\text { Flavanóis } \\
\left(\mathrm{mg} .100 \mathrm{~g}^{-1}\right)\end{array}$} & \multicolumn{5}{|c|}{ Tempo de fermentação (h) } \\
\hline & 0 & 24 & 48 & 96 & 120 \\
\hline Monômeros & 21,99 & 21,09 & 20,89 & 9,55 & 8,58 \\
\hline Dímeros & 10,07 & 9,76 & 9,89 & 5,78 & 4,66 \\
\hline Trímeros & 10,2 & 9,12 & 9,47 & 5,06 & 4,07 \\
\hline Tetrâmeros & 7,79 & 7,06 & 7,34 & 3,36 & 2,56 \\
\hline Pentâmeros & 5,31 & 4,74 & 4,906 & 2,14 & 1,63 \\
\hline Hexâmeros & 3,24 & 2,91 & 2,93 & 1,16 & 0,89 \\
\hline Heptâmeros & 1,31 & 1,36 & 1,33 & 0,46 & 0,33 \\
\hline Octâmeros & 0,63 & 0,61 & 0,69 & 0,25 & 0,17 \\
\hline Nonâmeros & 0,42 & 0,36 & 0,41 & 0,14 & 0,12 \\
\hline Decâmeros & 0,15 & 0,18 & 0,3 & 0 & 0 \\
\hline Undecâmeros & traços & traços & traços & nd & nd \\
\hline Total & 60,75 & 57,25 & 58,17 & 27,91 & 22,97 \\
\hline
\end{tabular}

Nd: não detectado. Fonte: Kealey et al. (1998).

sódio permitiu retenção 63,7\% maior de polifenóis em relação à fermentação realizada de forma convencional e a adição de $5 \mathrm{mg}$ de sulfato de cobre.100 $\mathrm{g}^{-1}$ de sementes, de $72,3 \%$, confirmando que enzimas como a polifenoloxidase e a glicosidase são de fato responsáveis pela redução do teor de polifenóis nesta etapa. Das amêndoas de cacau obtidas, foram produzidos chocolates que tiveram aceitação sensorial similar à de chocolates produzidos com amêndoas de cacau fermentadas convencionalmente. Ainda em relação à influência de enzimas presentes no cacau na degradação dos compostos fenólicos, Tomas-Barberán et al. (2007) avaliaram as condições ótimas para inativar a enzima polifenoloxidase em sementes de cacau in natura, por meio de calor úmido. As condições sob as quais houve o menor escurecimento enzimático foram as usadas no tratamento realizado a $95{ }^{\circ} \mathrm{C}$ por 5 min.. Kattenberg e Willemsen (2003 apud TOMAS-BARBERÁN et al., 2007) descreveram o uso de aquecimento por micro-ondas para impedir a atividade da polifenoloxidase em amêndoas de cacau fermentadas.

Aikpokpodion e Dongo (2010) estudaram o perfil da capacidade antioxidante do sistema, do primeiro ou sexto dia de fermentação, quando os compostos fenólicos são reduzidos. O conteúdo de catequina das sementes de cacau não reduziu durante a fermentação e os resultados mostraram que, apesar da perda dos polifenóis totais durante a fermentação, a concentração restante nas sementes é altamente suficiente para produzir uma alta capacidade antioxidante.

\subsubsection{Influência da secagem}

A secagem tem como principal objetivo interromper a fermentação e reduzir a umidade das amêndoas de cacau, tornando-as mais estáveis ao armazenamento.
Tal etapa deve ser iniciada imediatamente após a fermentação e deve ser adequadamente conduzida para evitar o desenvolvimento de fungos toxigênicos, que podem afetar o desenvolvimento do sabor característico de chocolate, além de causarem danos à saúde. Muitas das reações bioquímicas iniciadas na fermentação continuam durante a secagem, permitindo a redução do amargor, da adstringência e da acidez das amêndoas, além do escurecimento dos cotilédones, contribuindo com a formação dos precursores de sabor desejáveis de chocolate (BECKETT, 2009). A secagem ao sol permite a obtenção de produtos com melhor qualidade sensorial em relação à secagem realizada de forma artificial (FABORODE et al., 1995; EFRAIM et al., 2010). Efraim et al. (2010) demonstraram haver maior retenção de polifenóis na secagem natural, possivelmente por ser realizada em temperaturas mais brandas que na secagem artificial. Durante a secagem, a redução do teor de polifenóis é atribuída à reação de escurecimento enzimático causada pela polifenoloxidase que, nessa etapa, encontra condições ideais para sua atividade, seguida de escurecimento não enzimático decorrente da polimerização das quinonas resultantes e da acumulação de compostos insolúveis (HANSEN et al., 1998).

\subsubsection{Influência da torração}

A etapa de torração é fundamental para a obtenção das características de qualidade de chocolates (KLEINERT, 1994; LOPES et al., 2003). As condições de torração dependem de vários fatores, como a origem e o tipo da amêndoa, o período de colheita, os tratamentos anteriores à torração, além da umidade e do tamanho das amêndoas ou dos nibs (Pezoa-García, 1989; Brito, 2000; Lopes et al., 2003). Por sua vez, as reações químicas envolvidas são afetadas pelos parâmetros de 
tempo e temperatura de torração, e fatores como $\mathrm{pH}$, umidade e lipídios totais, bem como a presença, o tipo e os teores de compostos aromáticos, açúcares redutores e aminoácidos livres.

De acordo com Kealey et al. (2001), quanto maiores o tempo e a temperatura utilizados na torração, menores os teores de polifenóis dos produtos resultantes. Misnawi et al. (2002) verificaram diminuição de 3\% no teor de polifenóis totais durante a torração de liquor de cacau a $120^{\circ} \mathrm{C}$ por $45 \mathrm{~min}$, sugerindo que os polifenóis possam se ligar às pirazinas (compostos formados pela Reação de Maillard). Em outro estudo, Misnawi et al. (2004) verificaram que o aumento na concentração de polifenóis em liquor de cacau, além de diminuir a formação de pirazinas durante a torração, também causou redução na disponibilidade de aminoácidos livres e açúcares redutores para a formação de pirazinas, indicando que os polifenóis, além de se ligarem às pirazinas durante a torração, também podem se ligar aos compostos precursores da Reação de Maillard. Cabe destacar que a redução na concentração de pirazinas formadas praticamente não foi influenciada pelos tempos de torração estudados (15, 25, 35 e 45 min) (MISNAWI et al., 2004). Misnawi et al. (2005) concluíram que elevadas concentrações de polifenóis em liquor não torrado podem influenciar negativamente a formação de compostos desejáveis ao sabor.

Ortega et al. (2008) avaliaram o efeito de diversas etapas de processamento de amêndoas de cacau sobre os teores e o perfil dos compostos fenólicos. Foram avaliadas amêndoas fermentadas e secas, nibs torrados, liquor e pó de cacau do grupo Forastero, oriundos de Gana, África. Os autores encontraram teores mais altos de compostos fenólicos nos nibs torrados em relação aos demais produtos avaliados e, justificaram tal fato em função das operações de quebra das amêndoas e de torração dos nibs de cacau, as quais permitiriam, por meio da ruptura de membranas celulares, maior solubilidade e difusão dos compostos fenólicos. Outra possibilidade não considerada pelos autores seria que as amêndoas fermentadas e secas compreendem os cotilédones (nibs), o gérmen e a casca, sendo que os dois últimos correspondem a aproximadamente $12 \%$ do peso da amêndoa e possuem teores mais baixos de polifenóis que os cotilédones.

\subsubsection{Influência dos processos de alcalinização do pó de cacau}

A alcalinização é um tratamento que visa à modificação da cor e do sabor dos produtos de cacau, bem como a melhoria de solubilidade. Este processo envolve a exposição dos nibs, liquor ou pó de cacau natural a soluções alcalinas de bicarbonato de sódio ou potássio, ou de outros álcalis, alterando o pH de, em média, 5,5 (cacau natural) até 8,2 (pó alcalinizado). São obtidos pós de cacau ou liquors de diferentes tonalidades, de marrom claro a preto.

Gu et al. (2006) relataram haver menor quantidade de flavanóis (catequinas e procianidinas) em pó de cacau alcalinizado em relação ao natural. Andrés-Lacueva et al. (2008) determinaram o conteúdo de flavanóis monoméricos e de alguns flavonóis em diferentes marcas espanholas de cacau em pó. Estudaram a influência da alcalinização em dez amostras de cacau em pó natural contendo 10 a 12\% de manteiga, obtidas de amêndoas de cacau Forastero de diferentes variedades e origens. Todas as amostras foram alcalinizadas até $\mathrm{pH} \mathrm{7,2} \mathrm{e,} \mathrm{em} \mathrm{seguida,} \mathrm{tanto} \mathrm{o}$ cacau em pó alcalinizado como o natural foram utilizados para o processamento de diferentes produtos derivados. Os resultados mostraram concentrações de flavanóis superiores às de flavonóis em todos os pós avaliados. A (-)-epitecatequina foi o polifenol encontrado em maior quantidade nos pós de cacau, conforme reportado em outros estudos (KIM e KEENEY, 1984; LAMUELARAVENTÓS et al., 2005; GU et al., 2006). A faixa de valores foi de 116,02 a $730,26 \mu \mathrm{g} \cdot \mathrm{g}^{-1}$ para (-)-epitequatequina e de 81,40 a 447,62 $\mu \mathrm{g} \cdot \mathrm{g}^{-1}$ para (+)-catequina. Entretanto, valores mais baixos foram encontrados nos pós de cacau alcalinizados (180 a $380 \mu \mathrm{g} \cdot \mathrm{g}^{-1}$ de (-)-epitecatequina e 230 a $350 \mu \mathrm{g} \cdot \mathrm{g}^{-1}$ de (+)-catequina), indicando perda aproximada de $60 \%$ dos flavonoides, possivelmente por causa da alcalinização. Entre os flavanóis, a (-)-epitecatequina mostrou queda maior (67\%) que a $(+)$-catequina $(38 \%)$, resultando em uma troca do perfil original de flavanóis monoméricos, causada, possivelmente, pela epimerização da (-)-epitecatequina à (-)-catequina. Desta forma, o processo de alcalinização pode afetar a biodisponibilidade dos flavanóis do cacau, uma vez que a (-)-epicatequina apresenta maior absorção que a (+)-catequina. Quanto aos flavonóis, AndrésLacueva et al. (2008) demonstraram que houve, após alcalinização, maior perda de quercetina (86\%), seguida de quercetina-3-glucoronídio, quercetina-3-arabinosídio e isoquercetina, que mostraram quedas similares $(58,62$ e $61 \%$, respectivamente)

As alterações que ocorrem na etapa de alcalinização podem ser atribuídas à oxidação dos compostos fenólicos, que ocorre com o aumento do $\mathrm{pH}$, levando à formação de pigmentos marrons que são polimerizados em diferentes graus. Em particular, reações secundárias provocadas pela enzima polifenoloxidase envolvendo o-quinonas durante a fermentação também podem levar ao desenvolvimento da cor marrom durante a alcalinização (REEVES et al., 1988; GUYOT et al., 1996 apud ANDRÉS-LACUEVA et al., 2008)

Com isso, o processo de alcalinização provoca considerável diminuição da concentração de flavonoides em pó de cacau natural, além de mudanças no perfil 
de flavanóis monoméricos, afetando negativamente a atividade antioxidante e a biodisponibilidade dos polifenóis presentes (ANDRÉS-LACUEVA et al., 2008). Considerando que produtos elaborados com pó de cacau geralmente possuem menor teor de gorduras saturadas que tabletes de chocolate, devem-se otimizar as condições de alcalinização para minimizar a perda de polifenóis.

\subsubsection{Influência das etapas de fabricação do chocolate}

O chocolate pode ser definido como uma dispersão de partículas sólidas (açúcares, sólidos de cacau e sólidos de leite) em uma fase gordurosa contínua, que também contribui para o sabor e a cor, além de promover forma ao produto final (VISSOTTO et al., 1999). De acordo com Lawless e Hildegarde (1998), o sabor do chocolate é uma combinação única dos atributos aroma, gosto e textura. Para o completo desenvolvimento dessa combinação, as etapas de fermentação, torração e conchagem são de extrema importância (Hoskin e Dimick, 1994).

O processo convencional de fabricação de chocolate envolve, em sequência, as etapas de mistura dos ingredientes, refino, conchagem, temperagem, moldagem, resfriamento, desmoldagem e embalagem (BECKETT, 2009).

Estudos sugerem que, durante a fabricação de chocolates, ocorram reações de epimerização da (-)-epicatequina, a qual se transforma em (-)-catequina, composto não encontrado naturalmente nas sementes de cacau. Cooper et al. (2007) encontraram teores mais altos de (-)-catequina que de (+)-catequina em 68 amostras comerciais de chocolate, o que poderia afetar a biodisponibilidade dos flavanóis dos produtos de cacau, uma vez que a (-)-catequina apresenta menor biodisponibilidade que (+)-catequina (DONOVAN et al., 2006; COOPER et al., 2008). Contudo, ainda são escassos os trabalhos que tenham avaliado a influência das etapas específicas de fabricação de massa de chocolate nos polifenóis.

Poucos trabalhos foram encontrados relatando o efeito da conchagem na perda de polifenóis. A conchagem tem como objetivo permitir a volatilização do ácido acético formado durante a fermentação do cacau, além da diminuição da umidade proveniente dos ingredientes e da formação de aromas desejáveis por reações como a de Maillard (BECKETT, 2000).

Sulistyowati e Misnawi (2008) estudaram a atividade antioxidante de chocolate em função da concentração de álcali e da temperatura de conchagem. Os resultados demonstraram que ambos influenciaram o teor final total de polifenóis, sendo que o aumento da concentração do álcali e da temperatura de conchagem reduziu gradualmente as concentrações finais de polifenóis. Houve uma relação significativa entre a concentração do álcali e a temperatura de conchagem na concentração dos polifenóis. Entretanto, a diminuição da concentração de polifenóis em baixas concentrações de álcali durante a conchagem (abaixo de $5 \mathrm{~g} \cdot \mathrm{kg}^{-1}$ ) foi menos expressiva, indicando que a redução de polifenóis foi causada principalmente pela presença do álcali. Por outro lado, o aumento da concentração de álcali (15 g. $\mathrm{kg}^{-1}$ ) provocou aumento da oxidação dos polifenóis. Da mesma forma, o calor aplicado durante a conchagem também intensificou a oxidação. Essas duas condições resultaram em uma redução da concentração dos polifenóis após a conchagem a $80^{\circ} \mathrm{C}$, de 26,7 para $22,5 \mathrm{~g}$ de polifenóis. $\mathrm{kg}^{-1}$ de chocolate. Entretanto, foi sugerido que a redução nos teores de polifenóis foi causada mais por oxidação do que por hidrólise, uma vez que a maioria dos polifenóis sofre condensação, transformando-se em taninos, os quais são mais resistentes às reações de hidrólise. Foi demonstrada ainda redução mais intensa da atividade antioxidante dos polifenóis presentes no chocolate com a aplicação do calor por tempos longos, como 24 h, neste sistema complexo, no qual açúcar, leite, sal, baunilha e álcali estão presentes. Os autores mostraram que $1 \mathrm{~g}$ de bicarbonato de sódio reduziu em $17 \%$ a atividade antioxidante, enquanto que $15 \mathrm{~g}$ reduziram em $23 \%$. A redução da atividade antioxidante em razão do aumento da concentração de álcali nas temperaturas de conchagem entre 40 e $80{ }^{\circ} \mathrm{C}$ foi de 7 e 18\%, respectivamente, concluindo-se haver efeito sinérgico entre o calor e o álcali para a redução da atividade antioxidante, ou seja, o aumento da temperatura de conchagem e da concentração do álcali pode produzir efeito sinérgico na redução da atividade antioxidante.

\section{Conclusões}

Assim como já é conhecido o efeito antioxidante de chá, uva e outras frutas, a semente de cacau, o chocolate em pó e os chocolates amargos são ricos em compostos fenólicos. Por porção consumida, possuem teores mais altos de polifenóis entre outros alimentos. Os principais compostos fenólicos encontrados nas sementes de cacau estão classificados entres os taninos e os flavonoides, sendo os mais abundantes a (+)-catequina e a (-)-epicatequina (na forma de procianidinas monoméricas ou taninos condensados). Na presença de proteínas e carboidratos, os polifenóis se complexam, produzindo sensação de adstringência e amargor indesejáveis no chocolate. O pré-processamento das sementes de cacau e algumas etapas do processamento de chocolate foram tradicionalmente estabelecidos para eliminação dessa sensação e formação do sabor característico. Entretanto, a revisão do assunto demonstra que os parâmetros utilizados nas operações tradicionais de processamento de cacau e derivados levam à perda dos compostos fenólicos, que é desejável sob o ponto de vista de sabor, mas altamente indesejável em relação às propriedades 
Revisão: polifenóis em cacau e derivados: teores, fatores de variação e efeitos na saúde EFRAIM, P. et al.

antioxidante, cardioprotetora, anti-inflamatória, entre outras, quando da ingestão de bebidas ou produtos de cacau. As etapas do processo que mais contribuem para a destruição dos polifenóis são a fermentação das sementes de cacau e a alcalinização dos nibs e liquor. A epicatequina tem sido apresentada como o composto ativo do cacau responsável pelos efeitos benéficos à saúde vascular. Os teores de polifenóis encontrados nos produtos de cacau podem estar relacionados com a origem, a variedade do cacau e com parâmetros de processo, sendo o $\mathrm{pH}$ um dos mais importantes. A produção de chocolates ao leite e amargo apresenta um enorme potencial para inovação tecnológica, visto a necessidade da manutenção destes compostos pelos benefícios à saúde, sem prejuízo do sabor agradável e esperado, atributo de grande importância em produtos como o chocolate.

\section{Referências}

ACTICOA. How Does Acticoa Work. Disponível em: <http:// www.acticoa.com>. Acesso em: 15 fev. 2011.

ADAMSON, G.E.; LAZARUS, S.A.; MITCHELL, A.E.; PRIOR, R.L.; CAO, G.; JACOBS, P.H.; KREMERS, B.G.; HAMMERSTONE, J.F.; RUCKER, R.B.; RITTER, K.A.; SCHMITZ, H.H. HPLC Method for the Quantification of Procyanidins in Cocoa and Chocolate Samples and Correlation to Total Antioxidant Capacity. Journal of Agricultural and Food Chemistry, Washington, v. 47, n. 10, p. 4184-4188, 1999. PMid:10552788. http://dx.doi.org/10.1021/ jf990317m

AIKPOKPODION, P. E.; DONGO, L. N. Effects of fermentation intensity on polyphenols and antioxidant capacity of cocoa beans. International Journal of Sustainable Crop Production, Bangladesh, v. 5, n. 4, p. 66-70, 2010.

ALVES, A. B. Compostos Antioxidantes em Polpa de Tomate: Efeito do Processamento eda Estocagem. 2009. 145 f. Tese (Doutorado em Ciência de Alimentos)-Faculdade de Engenharia de Alimentos, Universidade Estadual de Campinas, Campinas.

ANDRES-LACUEVA, C.; MONAGAS, M.; KHAN, N.; IZQUIERDO-PULIDO, M.; URPI-SARDA, M.; PERMANYER, J.; LAMUELA-RAVENTOS, R. M. Flavanol and flavonol contents of cocoa powder products: influence of the manufacturing process. Journal of Agricultural and Food Chemistry, Washington, v. 56, n. 9, p. 3111-3117, 2008. PMid:18412367. http://dx.doi. org/10.1021/jf0728754

ARTS, I. C., HOLLMAN, P. C., FESKENS, E. J., BUENO DE MESQUITA, H. B.; KROMHOUT, D. Catechinintake and associated dietary and lifestyle factors in a representative sample of Dutch men and women. European Journal of Clinical Nutrition, London, v. 55, n. 2, p. 76-81, 2001. PMid:11305629. http://dx.doi.org/10.1038/sj.ejcn. 1601115

ARTS, I. C.; PUTTE, B.; HOLLMAN, P. C. Catechin contents of foods commonly consumed in The Netherlands. 1. Fruits, vegetables, staple foods, and processed foods. Journal of Agricultural and Food Chemistry, Washington, v. 48, n. 5, p. 1746-1751, 2000. PMid:10820089. http://dx.doi.org/10.1021/ jf000025h

ARTS, I. C. W.; HOLLMAN, P. C. H.; KROMHOUT, D. Chocolate as a source of tea flavanoids. The Lancet, London, v. 354, p. 488, 1999. http://dx.doi.org/10.1016/S0140-6736(99)02267-9

BALZER, J.; RASSAF, T.; HEISS, C.; KLEINBONGARD, P.; LAUER, T.; MERX, M.; HEUSSEN, N.; GROSS, H. B.; KEEN, C., SCHROETER, H.; KELM, M. Sustained Benefits in Vascular Function Through Flavanol-Containing Cocoa in Medicated Diabetic Patients: A Double-Masked, Randomized, Controlled Trial. Journal of the American College of Cardiology, New York, v. 51, n. 22, p. 2141-2149, 2008. PMid:18510961. http:// dx.doi.org/10.1016/j.jacc.2008.01.059

BECKETT, S. T. The science of chocolate. Cambridge: Royal Society of Chemistry. 2000. p. 31-47.

BECKETT, S. T. Industrial Chocolate Manufacture and Use. 4. ed. London: Wiley-Blackwell. 2009. 720 p.

BLOOR, S. J. Overview of methods for analysis an identification of flavonoids. Methods in Enzimology, Oxford, v. 335, p. 3-14, 2001. http://dx.doi.org/10.1016/S0076-6879(01)35227-8

BRAVO, L. Polyphenols: chemistry, dietary sources, metabolism and nutritional significance. Nutrition Reviews, New York, v. 56, n. 11, p. 317-333, 1998.

BRITO, E. S. Estudo de Mudanças Estruturais e Químicas Produzidas Durante Fermentação, Secagem e Torração do Cacau (TheobromaCacao L.); e Propostas de Tratamento Para o Melhoramento de Sabor. 2000. Tese (Doutor em Tecnologia de Alimentos)-Faculdade de Engenharia de Alimentos, Universidade Estadual de Campinas,Campinas.

COCOAVIA. CocoaproProducts. Disponível em: http://www. cocoavia.com/scientific-research-cocoavia/. Acesso em: 15 fev.2011.

COENTRÃO, P. A. M. Avaliação das Técnicas de Isolamento de Polifenóis: Aplicação em Amo COCOAVIA stras de Chocolate Meio Amargo. 2005. 110 f. Dissertação (Mestre em Química)-Faculdade de Química, Universidade Federal Fluminense, Niterói.

COUNET, C.; CALLEMIEN, D.; COLLIN, S. Chocolate and cocoa: New sources of trans-resveratrol and trans-piceid. Food Chemistry, Barking, v. 98, n. 4, p. 649-657, 2006.

COOPER, K.A.; CAMPOS-GIMÉNEZ, E.; ALVAREZ, D.J.; RYTZ, A.; NAGY, K.; WILLIAMSON, G. Predictive relationship between polyphenols and nonfat cocoa solids content of chocolate. Journal of Agricultural and Food Chemistry, Washington, v. 56, n.1, p. 260-265, 2008. PMid:18052039. http://dx.doi. org/10.1021/jf072153c

COOPER, K.A.; CAMPOS-GIMÉNEZ, E.; JIMÉNEZ-ALVAREZ, D.; NAGY, K.; DONOVAN, J. L.; WILLIAMSON, G. Rapid reversed 
Revisão: polifenóis em cacau e derivados: teores, fatores de variação e efeitos na saúde EFRAIM, P. et al.

phase-ultra performance liquid chromatography analysis of the major cocoa polyphenols and inter-relationships of their concentrations in chocolate. Journal of Agricultural and Food Chemistry, Washington, v. 55, p. 2841-2847, 2007. PMid:17362030. http://dx.doi.org/10.1021/jf063277c

CROSS, E.; VILLENEUVE, F.; VINCENT, J. C. Recherche d'un índice de fermentation du cacau. Café, Cacau, Thé, Paris, v. 16, n. 2, p. 109-113, 1982.

CROSS, E. Cocoa flavor development. The Manufacturing Confectioner, Princeton, v. 79, n. 2, p. 70-77, 1999.

DAGUENET, G.; PARVAIS, J. P. Ėtude comparative de La résistance a Phytophthora palmivora (Butl.) Butl. emend. Bras. et Grif. Detrois espèces du genre Theobroma. Mise enévidence de substances de type phytoalexinsresponsable de larésistanceinduite. Café, Cacao, Thé, Paris, v. 25, p. 181-190, 1991.

De PASCUAL-TERESA, S.; SANTOS-BUELGA, C.; RIVASGONZALO, J. C. Quantitative analysis of flavan-3-ols in Spanish foodstuffs and beverages. Journal of Agricultural and Food Chemistry, Washington, v. 48, n. 11, p. 5331-5337, 2000. PMid:11087482. http://dx.doi.org/10.1021/jf000549h

DEPRÉZ, S.; MILA, I.; HUNEAU, J. F.; TOME, D.; SCALBERT, A. Transportof proanthocyanidin dimer, trimer, and polymer across monolayers of human intestinal epithelial Caco-2 cells. Antioxidant and Redox Signaling, New York, v. 3, n. 6, p. 957 - 967, 2001. http://dx.doi.org/10.1089/152308601317203503

DONOVAN, J. L.; CRESPY, V.; OLIVEIRA, M.; COOPER, K. A.; GIBSON, B. B.; WILLIAMSON, G. (+)-Catechin is more bioavailable than (-)-catechin: relevance to the bioavailability of catechin from cocoa. Free Radical Research, New York, v. 40, n. 10, p. 1029-1034, 2006. PMid:17015247. http://dx.doi. org/10.1080/10715760600868545

EFRAIM, P. Estudo para Minimizar as Perdas de Flavonóides Durante a Fermentação de Sementes de Cacau para Produção de Chocolate. 2004. 110 f. Dissertação (Mestre em Tecnologia de Alimentos) - Faculdade de Engenharia de Alimentos, Universidade Estadual de Campinas, Campinas.

EFRAIM, P.; TUCCI, M. L.; GARCÍA, N. H. P.; HADDAD, R.; EBERLIN, M. Teores de compostos fenólicos de sementes de cacaueiro de diferentes genótipos. Brazilian Journal of Food Technology, Campinas, v. 9, n. 4, p. 229-236, 2006.

EFRAIM, P.; PEZOA-GARCÍA, N. H.; JARDIM, D. C. P.; NISHIKAWA, A.; HADDAD, R.; EBERLIN, M. N. Influência da fermentação e secagem de amêndoas de cacau no teor de compostos fenólicos e na aceitação sensorial. Ciência e Tecnologia de Alimentos, Campinas, v. 30, p. 142-150, 2010. Suplemento 1.

ESCARPA, A.; GONZALEZ, M. C. An overview of analytical chemistry of phenolic compounds in foods. Critical Reviews in Analytical Chemistry, London, v. 31, n. 2, p. 57-139, 2001. http://dx.doi.org/10.1080/20014091076695
FABORODE, M. O.; FAVIER, J. F.; AJAYI, O. A. On the effects of forced air drying on cocoa quality. Journal of Food Engineering, London, v. 25, n. 4, p. 455-472, 1995. http://dx.doi. org/10.1016/0260-8774(94)00018-5

FORSYTH, W. G. C; QUESNEL, V. C. Cacao glycosidase and color changes during fermentation. Journal of the Science of Food and Agriculture, London, v. 8, n. 9, p. 505-509, 1958. http://dx.doi.org/10.1002/jsfa.2740080902

GOTTI, R.; FURLANETTO, S.; PINZAUTI, S.; CAVRINI, V. Analysis of catechins in Theobroma cacao beans by cyclodextrinmodified micellareletrokinetic chromatography. Journal of Chromatography A, New York, v. 1112, p. 345-352, 2006.

GU, L.; KELM, M. A.; HAMMERSTONE, J. F. Concentrations of proanthocyanidins in common foods and estimations of normal consumption. Journal of Nutrition, New York, v. 134, p. 613-617, 2004.

GU, L.; HOUSE, S. E.; WU, S.; OU, B.; PRIOR, R. L. Procyanidin and Catechin Contents and Antioxidant Capacity of Cocoa and Chocolate Products.Journal of Agricultural and Food Chemistry, Washington, v. 53, n. 11, p. 4057-4061, 2006.

HALLIWELL, B. How to characterize a biological antioxidant. Free Radical Research Communications, New York, v. 9, p. 1-32, 1990. http://dx.doi.org/10.3109/10715769009148569

HAMMERSTONE, J. F.; LAZARUS, S. A.; SCHMITZ, H. H. Chocolate: Modern Science Investifates and Ancient Medicine. Journal of Nutrition, New York, n. 130, p. 2086s-2092s, 2000.

HANNEKENS, C. H. Platelet inhibitors and antioxidant vitamins in cardiovascular disease. American Heart Journal, Saint Louis, v. 128, p. 1333-1336, 1994.

HANSEN, C. E.; del OLMO, M.; BURRI, C. Enzyme activities in cocoa beans during fermentation. Journal of the Science of Food and Agriculture, London, v. 77, n. 2, p. 273-281, 1998. http:// dx.doi.org/10.1002/(SICI)1097-0010(199806)77:2<273::AIDJSFA40>3.0.CO;2-M

HEINRICH, U.; NEUKAM, K.; TRONNIER, H.; SIES, H.; WILHELM, S. Long-term ingestion of high flavanol cocoa provides photoprotection against UV-induced erythema and improves skin condition in women. Journal of Nutrition, New York, v. 136, p. 1-5, 2006.

HEISS, C.; FINIS, D.; KLEINBONGARD, P.; HOFFMANN, A.; RASSAF, T.; KELM, M.; SIES, H. Sustained increase in flowmediated dilation after daily intake of high flavanol cocoa drink over one week. Journal of Cardiovascular Pharmacology, New York, v. 49, n. 2, p. 74-80, 2007. PMid:17312446. http://dx.doi. org/10.1097/FJC.0b013e31802d0001

HERSHEY'S. Antioxidant Chocolate. Disponível em: http:// www.hersheys.com/nutrition/antioxidants.asp. Acesso em: 5 jan. 2010

HOLLMAN, P. C. H.; van HET HOF, K. H.; TIJBURG, L. B. M.; KATAN, M. B. Addition of milk does not affect the absorption of 
Revisão: polifenóis em cacau e derivados: teores, fatores de variação e efeitos na saúde EFRAIM, P. et al.

flavonols from tea in man. Free Radical Research, New York, v. 34, n. 3, p. 297-300, 2001. PMid:11264903. http://dx.doi. org/10.1080/10715760100300261

HOLT, R. R.; LAZARUS, S. A.; SULLARDS, M. C.; ZHU, Q. Y.; SCHRAMM, D. D.; HAMMERSTONE, J. F.; FRAGA, C. G. SCHMITZ, H. H.; KEEN, C. L. Procyanidindimer B2 (epicatechin(4 $\beta$-8)-epicatechin) in human plasma after the consumption of a flavanol-richcocoa. American Journal of Clinical Nutrition, Bethesda, v. 76, p. 798-804, 2002

HOSKIN, J. C.; DIMICK, P. S. Chemistry of flavour development in chocolate. In: BECKETT, S. T. (Ed.). Industrial Chocolate Manufacture and Use. London: Chapman \& Hall, 1994. p. 107.

JALIL, A.M. M.; ISMAIL, A. Polyphenols in cocoa and cocoa products: Is there a link between antioxidant properties and health? Molecules, Basel, Switzerland, v. 13, p. 2190-2219, 2008. PMid:18830150. http://dx.doi.org/10.3390/molecules13092190

JACOB, R. A.; BURRI, B. J. Oxidative damage and defense. American Journal of Clinical Nutrition, Bethesda, v. 63, p. 985S, 1996.

KEALEY, K. S.; SNYDER, R. M.; ROMACZYK, L. J.; GEYER, H. M.; HAMMERSTONE, J. F.; BUCK, M. M.; CIPOLLA, G. G. Method for Producing Fat and/or Solids from Cocoa Beans. USA $n$. PI 6.312,753. 2000.

KEALEY, K.S.; SNYDER, R.M.; ROMACZYK, L.J.; GEYER, H.M.; MEYERS, M.E.; WHITHCARE, E.J.; HAMMERSTONE, J.F.; SCHMITZ, H.H. Cocoa Components, Edible Products Having Enriched Polyphenol Content, Methods of Making Same and Medical Uses. USA n. PI 6.015.913. 2001.

KEALEY, K. S.; SNYDER, R. M.; ROMACZYK, L. J.; GEYER, H. M.; MEYERS, M. E.; WHITHCARE, E. J.; HAMMERSTONE, J. F.; SCHMITZ, H. H. Cocoa Components, Edible Products Having Enhanced Polyphenol Content, Methods of Making Same and Medical Uses. WO n. PI 98/09533. 1998.

KEEN, C. L. Chocolate: food as medicine/medicine as food. Journal of the American College of Nutrition, New York, v. 20, p. 436S-439S, 2001.

KIM, H.; KEENEY, P. G. (-)Epicatechin content in fermented and unfermented cocoa beans. Journal of Food Science, Chicago, v. 49 , n. 4, p. 1090-1092, 1984

KLEINERT, J. Cleaning, roasting and winnowing. In: BECKETT, S. T. Industrial Chocolate Manufacture and Use. 2. ed. London: Black Academic \& Professional, 1994.p. 55-69.

KWIK-URIBE, C. Potential Health Benefits of Cocoa Flavanols. The Manufacturing Confectioner, Princeton, v. 85, n. 10, p. 43-49, 2005.

LAMUELA-RAVENTÓS, R. M.; ROMERO-PÉREZ, A. I.; ANDRÉSLACUEVA, C.; TORNERO, A. Health effects of cocoa flavonoids. Food Science and Technology International, v. 11, n. 3, p. 159-176, 2005. http://dx.doi.org/10.1177/1082013205054498
LAWLESS, H. T.; HILDEGARDE, H. Sensory Evaluation of Food Principles and Practices. Aspen: Aspen, 1998.

LEE, K. W; KIM, Y. K.; LEE, H. J.; LEE, C. Y. Cocoa has more phenolic phytochemicals and a higher antioxidant capacity than teas and red wine. Journal of Agricultural and Food Chemistry, Washington, v. 51, n. 25, p. 7292-7295, 2003. PMid:14640573. http://dx.doi.org/10.1021/jf0344385

LEKSTRON, J. A; BELL, W. R. Aspirin in the prevention of thrombosis. Medicine, London, v. 70, p. 161-178, 1991.

LOPES, A. S.; PEZOA-GARCÍA, N. H.; VASCONCELOS, M. A. M. Avaliação das condições de torração após a fermentação de amêndoas de cupuaçu (TheobromagrandiflorumSchum) e cacau (Theobromacacao L.). Brazilian Journal of Food Technology, Campinas, v. 6, n. 2, p. 309-316, 2003.

LUNA, F.; CROUZILLAT, D.; CIROU, L.; BUCHELI, P. Chemical composition and flavor of Ecuadorian cocoa liquor. Journal of Agricultural and Food Chemistry, Washington, v. 50, n. 12, p. 3527-3532, 2002. PMid:12033823. http://dx.doi.org/10.1021/ jf0116597

MAO, T. K.; POWELL, J. W.; KEEN, C. L.; SHIMITZ, H. H; HAMMERSTONE, J. F.; GERSHWIN, M. E. The effect of cocoa procyanidins on the transcription and secretion of interleukin $1 \beta$ in peripheral blood mononuclear cells. Life Sciences, Elmsford, v. 66, n. 15, p. 1377-1386, 2000. http://dx.doi.org/10.1016/ S0024-3205(00)00449-5

MEIFREIN, M.; TANGUY, J. Sur le role dês composés phénoliques au cours de l'infection des cabosses de Theobroma cacao par Phytophthora. Café, Cacao, Thé, Paris, v. 11, p. 337-342, 1967.

MILLER, K. B.; STUART, D. A.; SMITH, N. L.; LEE, C. Y.; MCHALE, N. L. FLANAGAN, J. A.; OU, B.; HURST, W. J. Antioxidant Activity and Polyphenol and Procyanidin Contents of Selected Commercially Available Cocoa-Containing and Chocolate Products in the United States. Journal of Agricultural and Food Chemistry, Washington, v. 54, n. 11, p. 4062-4068, 2006.

MISNAWI; JINAP, S.; JAMILAH, B.; NAZAMID, S. Effects of cocoa liquor roasting on polyphenols content, their hydrophobicity and relation to astringency. ASEAN Food Journal, v. 12, p. 25-35, 2002. http://dx.doi.org/10.1016/j.foodchem.2003.06.005

MISNAWI, J.S.; JAMILAH, B.; NAZAMID, S. Effect of polyphenol concentration on pyrazine formation during cocoa liquor roasting. Food Chemistry, v. 85, n. 1, p. 73-80, 2004. http:// dx.doi.org/10.1016/j.foodchem.2003.06.005

MISNAWI; JINAP, S.; JAMILAH, B.; NAZAMID, S. Changes in polyphenol ability to produce astringency during roasting of cocoa liquor. Journal of the Science of Food and Agriculture, London, v. 85, n. 6, p. 917-924, 2005. http://dx.doi.org/10.1002/ jsfa. 1954

MOTAMAYOR, J. C.; LACHENAUD, P.; MOTA, J. W. S.; LOOR, R.; KUHN, D. N. Geographic and Genetic Population Differentiation 
Revisão: polifenóis em cacau e derivados: teores, fatores de variação e efeitos na saúde EFRAIM, P. et al.

of the Amazonian Chocolate Tree (Theobroma cacao L.). PLoS ONE, Chicago, v. 10, n. 3, 2008.

MURSU, J.; VOUTILAINEN, S; NURMI, T.; RISSANEN, T. H.; VIRTANEN, J. K.; KAIKKONEN, J.; NEN, K. N.; SALONEN, J. T. Dark chocolate consumption increases HDL cholesterol concentration and chocolate fatty acids may inhibit lipid peroxidation in healthy humans. Journal of Free Radicals in Biology and Medicine, New York, v. 37, n. 9, p. 13511359, 2004. PMid:15454274. http://dx.doi.org/10.1016/j. freeradbiomed.2004.06.002

NATSUME, M.; OSAKABE, N.; YAMAGISHI, M.; TAKIZAWA, T.; NAKAMURA, T.; MIYATAKE, H.; HATANO, T.; YOSHIDA, T. Analyses of polyphenols in cacao liquor, cocoa, and chocolate by normal-phase and reversed-phase HPLC. Bioscience, Biotechnology and Biochemistry, Tokyo, v. 64, n. 12, p. 2581-257, 2000. PMid:11210120. http://dx.doi.org/10.1271/ bbb. 64.2581

NEUKAM, K.; STAHL, W.; TRONNIER, H.; SIES, H.; HEINRICH, $\mathrm{U}$. Consumption of flavanol-rich cocoa acutely increases microcirculation in human skin. European Journal of Nutrition, Darmstadt, v. 46, n. 1, p. 53-56,2007. PMid:17164979. http:// dx.doi.org/10.1007/s00394-006-0627-6

NIEMENAK, N.; ROHSIUS, C.; ELWERS, S.; NDOUMOU, D. O.; LIEBEREI, R. Comparative study of different cocoa (Theobroma cacao L.) clones in terms of their phenolics and anthocyanins contents. Journal of Food Composition and Analysis, San Diego, v. 19, p. 612-619, 2006. http://dx.doi.org/10.1016/j. jfca.2005.02.006

NOJOSA, G. B. A.; RESENDE, M. L. V.; AGUILAR, M. A. G.; BEZERRA, K. M. T.; ANHERT, D. E. Componentes fenólicos e enzimas oxidativas em clones de Theobromacacao resistentes e suscetíveis a Crinipellis perniciosa. Fitopatologia Brasileira, Brasilia, v. 28, n. 2, p. 148-154,2003. http://dx.doi.org/10.1590/ S0100-41582003000200005

OMOKOLO, D. N.; TSALA NDZOMO, G.; DJOCGOUE, P. F. Changes in Carbohydrate, Amino Acid and Phenol Contents in Cocoa Pods from Three Clones after Infection with Phytophthoramegakarya Bra. and Grif. Annals of Botany, London, v. 77, n. 2, p. 153 - 158,1996. http://dx.doi.org/10.1006/ anbo.1996.0017

ORTEGA, N.; ROMERO, M. P.; MACIA, A.; REGUANT, J.; ANGLES, N.; MORELLO, J. R. Obtention and characterization of phenolic extracts from different cocoa sources. Journal of Agriculture and Food Chemistry, Washington, v. 56, n. 20, p. 9621-9627, 2008. PMid:18821769. http://dx.doi.org/10.1021/ jf8014415

OSAKABE, N.; YAMAGISHI, M.; SANBONGI, C.; NATSUME, M.; TAKIZAWA, T.; OSAWA, T. Antioxidative substances in cacao liquor. Journal of Nutritional Science Vitaminology, Tokyo, $v$. 44, n. 2, p. 313-21, 1998.
PETERSON, J.; DWYER, J. Flavonoids: Dietary occurrence and biochemical activity. Nutrition Research, New York, v. 18, n. 12, p. 1995-2018, 1998. http://dx.doi.org/10.1016/S02715317(98)00169-9

PEZOA-GARCÍA, N. H. Contribuition a l'étuded'um Capteur por Controlerem Continu Procede de Torréfaction. 1989. 170 f. These (Docteur)-Université de Technologie de Compiegne, Compiegne.

PICKENHAGEN, W.; DIETRICH, P.; KEIL, B.; POLONSKY, J.; NOUAILLE, F.; LEDERER, E. Identification of the bitter principle from cocoa. Helvetica Chimica Acta, Basel, v. 58, n. 4, p. 1078-1086, 1975. PMid:1158737. http://dx.doi.org/10.1002/ hlca. 19750580411

PIRES, J. L. Avaliação Quantitativa e Molecular de Germoplasmapara o Melhoramento de Cacaueiro com Ênfase na Produtividade, Qualidade dos Frutos e Resistência à Doenças. 2003. 226 f. Tese (Doutorado em Genética e Melhoramento)-Universidade Federal de Viçosa, Viçosa.

PORTER, L. J., MA, Z.; CHANG, G. Cacao procyanidins: major flavonoids and identification of some minor metabolites. Phytochemistry, New York, v. 30, n. 5, p. 1657-1663,1991. http:// dx.doi.org/10.1016/0031-9422(91)84228-K

RAMIREZ-SANCHEZ, I.; MAYA, L.; CEBALLOS, G.; VILLARREAL, F. Fluorescent detection of (-)-epicatechin in microsamples from cacao seeds and cocoa products: Comparison with FolinCiocalteu method. Journal of Food Composition and Analysis, San Diego, v. 23, n. 8, p. 790-793. 2010. PMid:21297935. http:// dx.doi.org/10.1016/j.jfca.2010.03.014

REIN, D.; PAGLIERONI, T. G.; WUN, T.; PEARSON, D. A.; SCHMITZ, H. H.; GOSSELIN, R.; KEEN, C. L. Cocoa inhibits platelet activation and function. American Journal of Clinical Nutrition, Bethesda, v. 72, n. 1, p. 30-35, 2000.

RICHELLE, M.; TAVAZZI, I.; ENSLEN, M.; OFFORD, E. A. Plasma kinetics in man of epicatechin from black chocolate. European Journal of Clinical Nutrition, London, v. 53, p. 22-26,1999. PMid:10048796. http://dx.doi.org/10.1038/sj.ejcn.1600673

SANBONGI, C.; OSAKABE, N.; NATSUME, M.; TAKIZAWA, T.; GOMI, S.; OSAWA, T. Antioxidative polyphenols isolated from Theobromacacao. Journal of Agricultural and Food Chemistry, Washington, v. 46, n. 2, p. 454-457, 1998. PMid:10554262. http:// dx.doi.org/10.1021/jf970575o

SANCHEZ-RABANEDA, O.; JAUREGUI, I.; CASALS, C. ANDRÉSLACUEVA, C.; IZQUIERDO-PULIDO, M.; LAMUELA-RAVENTÓS, R. M. Liquid chromatographic/electrospray ionization tandem mass spectrometric study of the phenolic composition of cocoa (Theobromacacao L.). Journal of Mass Spectrometry, New York, v. 38, n. 1, p. 35-42,2003. PMid:12526004. http://dx.doi. org/10.1002/jms.395

SCHNORR, O.; BROSSETTE, T.; MOMMAB, T. Y.; KLEINBONGARD, P.; KEEN, C. L.; SCHROETER, H.; SIES, H. Cocoa flavanols lower vascular arginase activity in human endothelial cells in 
Revisão: polifenóis em cacau e derivados: teores, fatores de variação e efeitos na saúde EFRAIM, P. et al.

vitro and in erythrocytes in vivo. Archives of Biochemistry and Biophysics, New York, v. 476, n. 2, p. 211-215,2008. PMid:18348861. http://dx.doi.org/10.1016/j.abb.2008.02.040

SCHRAMM, D. D.; KARIM, M.; SCHRADER, H. R.; HOLT, R. R.; KIRKPATRICK, N. J.; POLAGRUTO, J. A.; ENSUNSA J. L.; SCHMITZ, H. H.; KEEN, C. L. Food effects on the absorption and pharmaco kinetics of cocoa flavanols. Life Sciences, Oxford, v. 73, n. 7, p. 857-869, 2003. http://dx.doi.org/10.1016/S00243205(03)00373-4

SCHROETER, H.; HEISS, C.; BALZER, J. (-)-Epicatechin mediates beneficial effects of flavanol-rich cocoa on vascular function in humans. Proceedings of the National Academy of Sciences (U.S.A), v. 103, p. 1024-1029, 2006. PMid:16418281. PMCid:1327732. http://dx.doi.org/10.1073/pnas.0510168103

SEIGLER, D. S. Overview of functional foods: Emphasis on probiotic bacteria. International Dairy Journal, Barking, v. 8, n. 5, p. 341-347, 1995

SERAFINI, M.; GHISELLI, A.; FERRO-LUZZI, A. In vivo antioxidant effect of green and black tea in man. European Journal of Nutrition, London, v. 50, n. 1, p. 28-32, 1996.

SERRA-BONVEHÍ, J.; VENTURA COLL, F. Evaluation of bitterness and astringency of polyphenolic compounds in cocoa powder. Food Chemistry, v. 60, n. 3, p. 365-370, 1997. http://dx.doi. org/10.1016/S0308-8146(96)00353-6

SIES, H. Oxidative stress: from basic research to clinical application. American Journal of Medicine, NewYork, v. 91, n. 3, p. 31S-38S, 1991

STEINBERG, F. M.; BEARDEN, M. M.; KEEN, C. L. Cocoa and chocolate flavonoids: Implications for cardiovascular health. Journal of the American Dietetic Association, Chicago, v. 103, n. 2, p. 215-223, 2003. PMid:12589329. http://dx.doi. org/10.1053/jada.2003.50028

SULISTYOWATI; MISNAWI. Effects of alkali concentration and conching temperature on antioxidant activity and physical properties of chocolate. International Food Research Journal, Malaysia, v. 15, n. 3, p. 297-304, 2008.

TOMAS-BARBERÁN, F. A.; CIENFUEGOS-JOVELLANOS, E.; MARIN, A.; MUGUERZA, B.; GIL IZQUIERDO, A.; CERDAA, B.; ZAFRILLA, P.; MORILLAS, J.; MULERO, J.; IBARRA, A.; PASAMAR, M.; RAMOAN, D.; ESPIN, J. C. A new process to develop a cocoa powder with higher flavonoid monomer content and enhanced bioavailability in healthy humans. Journal of Agricultural and Food Chemistry, Washington, v. 55, p. 39263935, 2007

Van HET HOF, K. H.; KIVITIS, G. A. A.; WESTSTRATE, J. A.; TIJBURG, L. B. M. Bioavailability of catechins from tea: the efect of milk. European Journal of Clinical Nutrition, London, v. 52, n. 5, p. 356-359, 1998. PMid:9630386. http://dx.doi.org/10.1038/ sj.ejcn. 1600568
VINSON, J.; PROCH, J.; BOSE, P.; MUCHLER, S.; TAFERA, P.; SHUTA, D.; SAMMAN, N.; AGBOR, G. Chocolate is a powerful ex vivo and in vivo antioxidant, an antiatherosclerotic agent in an animal model and a significant contributor to antioxidants in the European and American diets. Journal of Agricultural and Food Chemistry, Washington, v. 54, n. 21, p. 8071-8076, 2006. PMid:17032011. http://dx.doi.org/10.1021/jf062175j

VISSOTTO, F. Z.; LUCCAS, V.; BRAGAGNOLO, N.; TURATTI, J. M.; GRIMALDI, R.; FIGUEIREDO, M. S. Caracterização físicoquímica de chocolates comerciais elaborados com gorduras alternativas. Brazilian Journal of Food Technology, Campinas, v. 21, n. 2, p. 139-148, 1999.

WANG, J. F.; SCHRAMM, D. D.; HOLT, R. R.; ENSUNSA, J. L.; FRAGA, C. G.; SCHMITZ, H. H; KEEN, C. L. A dose-response effect from chocolate consumption on plasma epicatechin and oxidative damage. Journal of Nutrition, New York, v. 130, n. 8, p. 2115S-2119S, 2000.

WATERHOUSE, A. L.; SIRLEY, J. R.; DONOVAN, J. L. Antioxidants in chocolate. The Lancet, London, n. 348, p. 834, 1996.

WILLIAMSON, G.; MANACH, C. Bioavailability and bioefficacy of polyphenols in humans. II. Review of 93 intervention studies. American Journal of Clinical Nutrition, Bethesda, v. 81, p. 243S-255S, 2005. Suplemento 1.

WOLLGAST, J.; ANKLAN, E. Polyphenols in chocolate: is there a contribution to human health? Food Research International, Essex, v. 33, n. 6, p. 449-459, 2000a.

WOLLGAST, J.; ANKLAM, E. Review on polyphenols in Theobroma cacao: changes in composition during the manufacture of chocolate and methodology for identification and quantification. Food Research International, Essex, v. 33, n. 6 , p. 423-447, 2000b.

YILMAZ, Y. Novel uses of catechins in foods. Trends in Food Science and Technology, Cambridge, v. 17, n. 2, p. 64-71,2006. PMid:21299575. http://dx.doi.org/10.1016/j.tifs.2005.10.005

ZHU, Q. Y.; HOLT, R. R.; LAZARUS, S. A.; ENSUNSA, J. L.; HAMMERSTONE, J. F.; SCHMITZ, H. H.; KEEN, C. L. Stability of the flavan-3-ols epicatechin and catechin and related dimericprocyanidins derived from cocoa. Journal of Agriculture and Food Chemistry, Washington, v. 50, n. 6, p. 1700-1705, 1998. PMid:11879061. http://dx.doi.org/10.1021/jf0112280

ZUMBÉ, A. Polyphenols in cocoa: are there health benefits? BNF Nutrition Bulletin, London, v. 23, n. 1, p. 94-102, 1998. http:// dx.doi.org/10.1111/j.1467-3010.1998.tb01088.x 